\title{
Wave based method for free vibration analysis of ring stiffened cylindrical shell with intermediate large frame ribs
}

\author{
Meixia Chen, Jianhui Wei*, Kun Xie, Naiqi Deng and Guoxiang Hou \\ School of Naval Architecture and Ocean Engineering, Huazhong University of Science and Technology, Wuhan, \\ Hubei, China
}

Received 5 September 2012

Revised 29 October 2012

Accepted 14 November 2012

\begin{abstract}
Wave based method which can be recognized as a semi-analytical and semi-numerical method is presented to analyze the free vibration characteristics of ring stiffened cylindrical shell with intermediate large frame ribs for arbitrary boundary conditions. According to the structure type and the positions of discontinuities, the model is divided into different substructures whose vibration field is expanded by wave functions which are exactly analytical solutions to the governing equations of the motions of corresponding structure type. Boundary conditions and continuity equations between different substructures are used to form the final matrix to be solved. Natural frequencies and vibration mode shapes are calculated by wave based method and the results show good agreement with finite element method for clamped-clamped, shear diaphragm - shear diaphragm and free-free boundary conditions. Free vibration characteristics of ring stiffened cylindrical shells with intermediate large frame ribs are compared with those with bulkheads and those with all ordinary ribs. Effects of the size, the number and the distribution of intermediate large frame rib are investigated. The frame rib which is large enough is playing a role as bulkhead, which can be considered imposing simply supported and clamped constraints at one end of the cabin and dividing the cylindrical shell into several cabins vibrating separately at their own natural frequencies.
\end{abstract}

Keywords: Wave based method, semi-analytical and semi-numerical method, cylindrical shell with intermediate large frame ribs, free vibration analysis

\section{Introduction}

Ring stiffened cylindrical shells are widely used in many structure applications such as aeronautic, aerospace, underwater vessel and so on. Cylindrical shells are usually divided into several short cabins by bulkheads, as model M1 shown in Fig. 5, which is not conducive to overall and equipments layout especially the layout of large equipment module. With advantages of high utilization of space and light structure weight, intermediate large frame ribs as model M2 shown in Fig. 5, instead of bulkheads, are used to maintain the characteristics of strength and stability which leads to changes of vibration characteristics.

The free vibration characteristics of cylindrical shells have received much attention, ranging from shear diaphragm - shear diaphragm boundary conditions to arbitrary boundary conditions, from cylindrical shells to ring stiffened cylindrical shells, from cylindrical shells without bulkheads to those with bulkheads. Investigations about

\footnotetext{
*Corresponding author: Jianhui Wei, School of Naval Architecture and Ocean Engineering, Huazhong University of Science and Technology, Wuhan 430074, Hubei, China. Tel.: +86 1399566 4256; Fax: +86 0278754 2416; E-mail: wjhhust@ hust.edu.cn.
} 
the free vibration characteristics of cylindrical shells have been summarized in $[1,2]$ and those with arbitrary boundary conditions have been investigated in [3-7]. With rings or stringers "smeared out", cylindrical shells with stiffeners are treated as orthotropic cylindrical shells [8-12]. The stiffeners must be equally and closely distributed and also with the same depth and width and large errors will be introduced if the stiffeners are large. And also this method is not applicable at mid and high frequencies if the wavelength and the rib spacing are in the same order for neglecting wave transmission and reflection at the discontinuities. Thein Wah [13] treats the stiffeners as discrete members. While only even spaced stiffeners with small size for simply supported boundary conditions can be dealt with for the reason that the motions of the stiffeners are described by the equations of motions of beams and the displacements at the positions of stiffeners are expanded as trigonometric functions which satisfy simply supported boundary conditions. All these research focus on free vibration characteristics of cylindrical shells without large discontinuities such as bulkheads and large intermediate large frame ribs and so on.

Wave propagation through cylinder/plate junctions is presented in Tso [14] and equilibrium and compatibility conditions between cylinder shell and circular plate are established. The free vibration characteristics of coupled cylindrical-conical shells with bulkheads have been analyzed in [15] where the ring stiffened cylindrical shells are treated as orthotropic cylindrical shells with rings "smeared out" which can only give an accuracy prediction of natural frequencies for cylindrical shells with even spaced stiffeners of small sizes in low frequency.

Wave based method (WBM) is first proposed in [16] for prediction of the steady-state dynamics analysis of coupled vibro-acoustic systems which enables accurate predictions in the mid-frequency range. WBM can be understood as a semi-analytical and semi-numerical method which is computationally less demanding than corresponding element based models. In contrast with the finite element method (FEM), in which the dynamic field variables within each element are expanded in terms of local, non-exact shape functions, usually polynomial approximation, the dynamic field variables in each substructure in WBM are expressed as wave function expansions which exactly satisfy the governing equations. Modeling of the vibro-acoustic coupling between the pressure field in an acoustic cavity with arbitrary shape and the out-of-plane displacement of a flat plate with arbitrary shape was discussed in [17] and the unbounded domain was discussed in [18].

In this paper, WBM model, which can deal with cylindrical shells with uneven spaced stiffeners with different sizes, especially large frame ribs which can't be described by the beam model, is developed to analyze free vibration characteristics of ring stiffened cylindrical shells with intermediate large frame ribs for arbitrary boundary conditions. The first part reviews the work already done about the free vibration characteristics of cylindrical shells. WBM models of ring stiffened cylindrical shells with intermediate large frames and bulkheads are described in the second part. Numerical results are compared with finite element method to show the validity of WBM model and free vibration characteristics of ring stiffened cylindrical shells with intermediate large frame ribs are discussed in the third part. Finally some conclusions are made in the last part.

\section{Basic concept of wave based method}

Wave based method (WBM) is developed for free vibration analysis of ring stiffened cylindrical shells with intermediate large frame ribs and those with bulkheads. As a semi-analytical and semi-numerical method, WBM model needs to be divided into different substructures according to the type of structures (beams, plates, shells, etc) which is similar to "element" in the element based method. In contrast with the finite element method (FEM), in which the dynamic field variables within each element are expanded in terms of local, non-exact shape functions, usually polynomial approximation, the dynamic field variables within each substructure in WBM model are expressed as wave function expansions, which are exact analytical solutions to the governing dynamic equations of the substructure. Boundary conditions and continuity conditions between different substructures are used to form the final matrix to calculate the natural frequencies. After natural frequencies have been located accurately, wave function contribution factors can be determined to calculate the vibration mode shape of the structure.

Similar to the finite element method, several steps are needed to construct a WBM model as follows:

1. Divide the whole model into different substructures. Different governing equations are used for different types of structure, such as beams, plates and shells. Also different physical properties and the positions of the discontinuities where coupling effects occur need to be considered. 


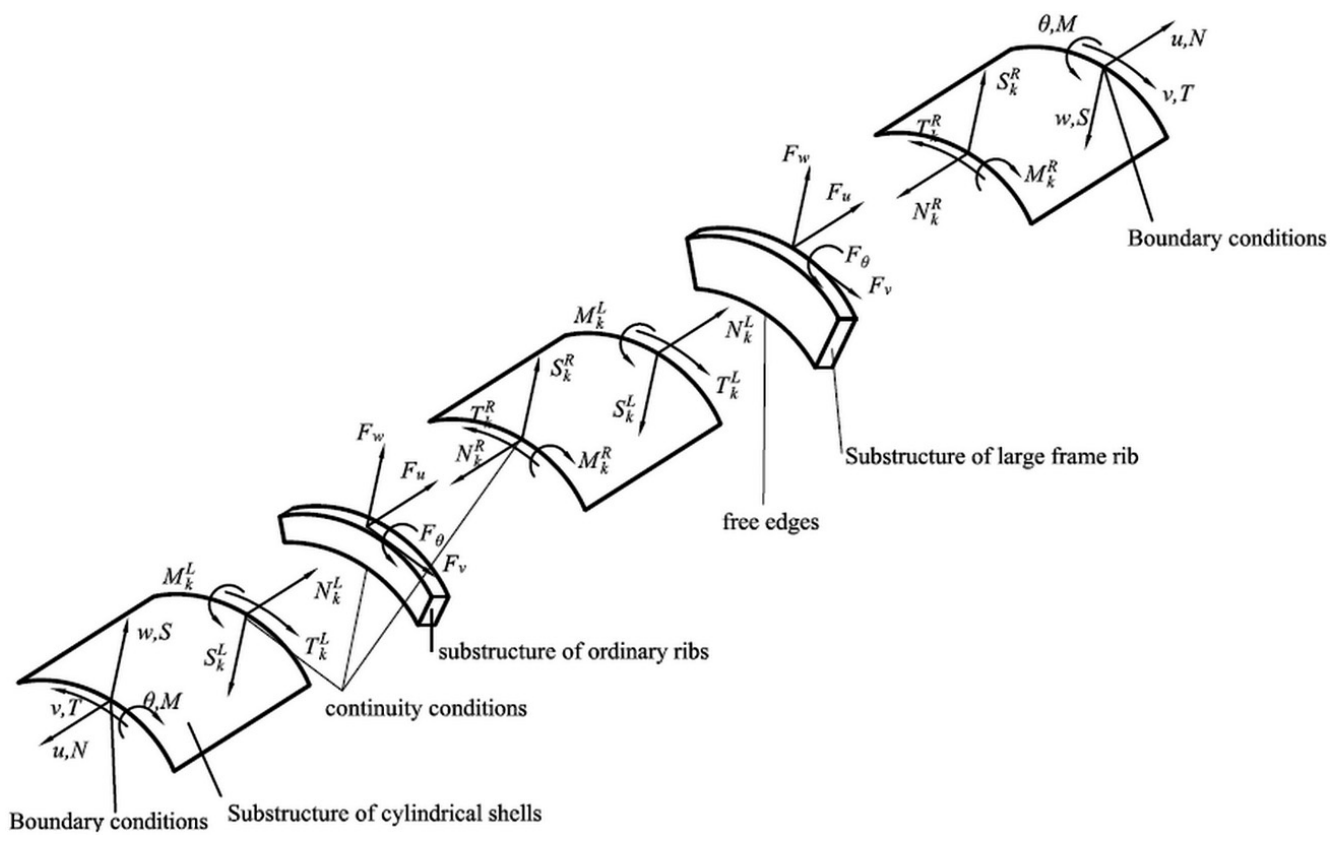

Fig. 1. Substructure divisions of cylindrical shells with intermediate large frame ribs.

2. Select suitable wave functions for each substructure. The dynamic field variables, such as the displacement, the velocity and so on, can be expanded by the wave functions which are analytical solutions to the governing equations of the substructures.

3. Form the final matrix to be solved according to boundary conditions and continuity conditions between different substructures. Eight specified boundary conditions and eight continuity conditions between different substructures, including forces and displacements, are used to form the final matrix.

4. Solve the final matrix to get the natural frequencies and the wave function contribution factors. The size of the matrix depends on the total number of substructures and the number of wave function expansions in each substructure. Compared with FEM model, the final size of matrix formed by WBM model is much smaller than FEM as the number of substructures is far more less than the number of elements.

5. Post-processing. The dynamic field variables can be obtained with the wave function contribution factors, such as the displacement, stress, strain and so on.

In this paper, WBM model is developed to analyze free vibration characteristics of ring stiffened cylindrical shells with intermediate large frame ribs for arbitrary boundary conditions. The cylindrical shell, the motions of which are described by the equations of Donnell-Mushtari theory, is divided into substructures according to the positions of discontinuities. The ordinary ribs, the intermediate large frame ribs and the bulkheads are divided into separate substructures the motions of which are described by the equations of circular plates. It is worth noting that the equations of motions of annular circular plates are used to describe the motions of ordinary ribs which is more accurate than beam model used in [13] especially for intermediate large frame ribs. The dynamic field variables in the substructures of cylindrical shells are expanded by wave functions given in [13] and those in substructures of ordinary ribs, large frame ribs and bulkheads are expanded by wave functions given in [14]. Then equilibrium and compatibility conditions between cylinder shell and ordinary ribs, large frame ribs and bulkheads are established. Combined with boundary conditions of the cylindrical shell and those of the free edges of large frame ribs, the final matrix can be formed to solve the natural frequencies.

\subsection{Substructure division of ring-stiffened cylindrical shells}

Substructure divisions of ring-stiffened cylindrical shells with intermediate large frame ribs are shown in Fig. 1. Cylindrical shells and annular circular plates are main types of structures composing the WBM model of ringstiffened cylindrical shell with intermediate large frame ribs. If there exists $N_{b}$ ordinary ribs and $N_{a}$ intermediate 
large frame ribs, the cylindrical shell is divided into $\left(N_{b}+N_{a}+1\right)$ segments so the total number of substructure in the WBM model is $\left(2 N_{b}+2 N_{a}+1\right)$ with $\left(N_{b}+N_{a}+1\right)$ substructures describing the motions of cylindrical shells, $N_{b}$ substructures describing the motions of ordinary ribs and $N_{a}$ substructures describing the motions of intermediate large frame ribs. For ring-stiffened cylindrical shells with bulkheads, similar substructure division can be obtained. The difference is that if $N_{c}$ bulkheads exist in the cylindrical shell, $\left(2 N_{b}+2 N_{c}+1\right)$ substructures can be obtained with $N_{c}$ substructures describing the motions of bulkheads. In both cases, the total number of segments of cylindrical shells is denoted as $N$ in the following analysis.

Various equations of motions for cylinder shells have been derived and are summarized by Leissa [1]. In this work, Donnell-Mushtari equations are used to describe the motions of cylindrical shells as follows:

$$
\begin{aligned}
& \frac{\partial^{2} u}{\partial x^{2}}+\frac{1-v}{2} \frac{\partial^{2} u}{\partial \phi^{2}}+\frac{1+v}{2} \frac{\partial^{2} v}{\partial x \partial \phi}+v \frac{\partial w}{\partial x}-\frac{\rho a^{2}\left(1-v^{2}\right)}{E} \frac{\partial^{2} u}{\partial t^{2}}=0 \\
& \frac{1+v}{2} \frac{\partial^{2} u}{\partial x \partial \phi}+\frac{\partial^{2} v}{\partial \phi^{2}}+\frac{1-v}{2} \frac{\partial^{2} v}{\partial x^{2}}+\frac{\partial w}{\partial \phi}-\frac{\rho a^{2}\left(1-v^{2}\right)}{E} \frac{\partial^{2} v}{\partial t^{2}}=0 \\
& v \frac{\partial u}{\partial x}+\frac{\partial v}{\partial \phi}+w+k\left(\frac{\partial^{4} w}{\partial x^{4}}+2 \frac{\partial^{4} w}{\partial x^{2} \partial \phi^{2}}+\frac{\partial^{4} w}{\partial \phi^{4}}\right)+\frac{\rho a^{2}\left(1-v^{2}\right)}{E} \frac{\partial^{2} w}{\partial t^{2}}=0
\end{aligned}
$$

The radius of the cylindrical shell is designated by $a$, and the thickness by $h . k=h^{2} / 12 a^{2}, u, v, w$ are the axial, circumferential and outward normal displacements, the axial and circumferential coordinates are $x, \phi, x=\bar{x} / a$. The mass density of the shell's material is designated by $\rho$, Young's modulus by $E$ and Poisson's ratio by $v$.

The ordinary ribs, intermediate large frame ribs and the bulkheads are all treated as separate substructures the governing equations of which are the same, all described by the equations of circular plates whose bending and inplane motions are described in Eq. (2). Annular circular plate with inner radius $a_{1}$ and outer radius $a$ (also the radius of the cylindrical shell) which is used to establish the mathematical model of ordinary rib and intermediate large frame rib is shown in Fig. 2. The axial displacement $w_{p, i}$, radial displacement $u_{p, i}$ and circumferential displacement $v_{p, i}$ of the plate in polar coordinates are also shown in Fig. 2. $\theta_{p, i}=\partial w_{p, i} / \partial r$ is the twist angle. The subscript $i=1,2$ denotes the annular circular plates and the circular plates respectively. The difference between the annular circular plates and the circular plates is that the there are no free edges at the inner radius of circular plate.

$$
\left\{\begin{array}{l}
\frac{\partial}{\partial r}\left(\frac{\partial u_{p}}{\partial r}+\frac{u_{p}}{r}+\frac{1}{r} \frac{\partial v_{p}}{\partial \theta}\right)-\frac{1-v_{p}}{2 r} \frac{\partial}{\partial \theta}\left(\frac{\partial v_{p}}{\partial r}+\frac{v_{p}}{r}-\frac{1}{r} \frac{\partial u_{p}}{\partial \theta}\right)=\frac{\rho_{p}\left(1-v_{p}^{2}\right)}{E_{p}} \frac{\partial^{2} u_{p}}{\partial t^{2}} \\
\frac{1}{r} \frac{\partial}{\partial \theta}\left(\frac{\partial u_{p}}{\partial r}+\frac{u_{p}}{r}+\frac{1}{r} \frac{\partial v_{p}}{\partial \theta}\right)+\frac{1-v_{p}}{2} \frac{\partial}{\partial r}\left(\frac{\partial v_{p}}{\partial r}+\frac{v_{p}}{r}-\frac{1}{r} \frac{\partial u_{p}}{\partial \theta}\right)=\frac{\rho_{p}\left(1-v_{p}^{2}\right)}{E_{p}} \frac{\partial^{2} v_{p}}{\partial t^{2}} \\
\frac{\partial^{4} w}{\partial^{4} r}+2 \frac{\partial^{4}}{\partial r^{2} \partial \theta^{2}}+\frac{\partial^{4} w}{\partial^{4} \theta}-\frac{\rho_{p} \omega^{2} h_{p}}{D_{p}} w_{p}=0
\end{array}\right.
$$

$h_{p, i}$ is the plate thickness. $E_{p, i}, \rho_{p, i}$ and $\nu_{p, i}$ are respectively the Young's modulus, density and Poisson's ratio. $D_{p, i}=E_{p, i} h_{p, i}^{3} / 12\left(1-v_{p, i}^{2}\right)$ is the flexural rigidity.

\subsection{Selection of wave functions}

For a modal vibration, the axial, circumferential and outward normal displacements of the cylindrical shells, the ordinary ribs, the intermediate large frame ribs and the bulkheads are all usually expanded as follows:

$$
\left.\begin{array}{l}
w=\sum_{i=1}^{n_{s}} A_{i} \Psi_{w i}(x) \sin (n \phi) \cos \omega t \\
v=\sum_{i=1}^{n_{s}} B_{i} \Psi_{v i}(x) \cos (n \phi) \cos \omega t \\
u=\sum_{i=1}^{n_{s}} C_{i} \Psi_{u i}(x) \sin (n \phi) \cos \omega t
\end{array}\right\}
$$




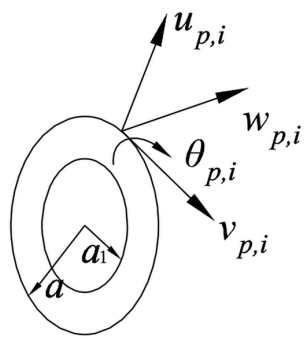

Fig. 2. Displacement of annular circular plate.

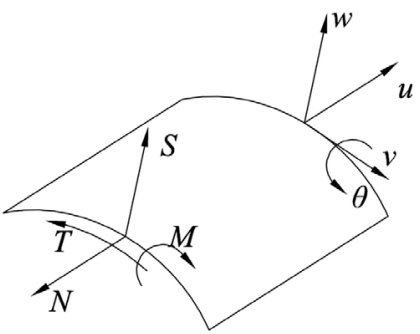

Fig. 3. Displacement and force constraints of cylindrical shells.

For the cylindrical shell, $\Psi_{w i}(x, \phi), \Psi_{v i}(x, \phi), \Psi_{u i}(x, \phi)$ are the structure wave functions which exactly satisfy Eq. (1) for a specified circumferential wave number $n, A_{i}, B_{i}, C_{i}$ are the wave contribution factors. $n_{s}$ is the number of wave functions designating the wave propagation in the axial direction.

To insure the WBM model to converge towards the exact solution, the selection of suitable wave function is quite important. According to analysis in [13], a set of wave functions describing the free vibration of cylindrical shell is selected as follows:

$$
\begin{aligned}
& \Psi_{w 1}=\Psi_{v 1}=\Psi_{u 1}=e^{\lambda_{1} x}, \Psi_{w 2}=\Psi_{v 2}=\Psi_{u 2}=e^{-\lambda_{1} x} \\
& \Psi_{w 3}=\Psi_{v 3}=\Psi_{u 3}=\cos \lambda_{2} x, \Psi_{w 4}=\Psi_{v 4}=\Psi_{u 4}=\sin \lambda_{2} x \\
& \Psi_{w 5}=\Psi_{v 5}=\Psi_{u 5}=e^{\lambda_{3} x} \cos \lambda_{4} x, \Psi_{w 6}=\Psi_{v 6}=\Psi_{u 6}=e^{\lambda_{3} x} \sin \lambda_{4} x \\
& \Psi_{w 7}=\Psi_{v 7}=\Psi_{u 7}=e^{-\lambda_{3} x} \cos \lambda_{4} x, \Psi_{w 8}=\Psi_{v 8}=\Psi_{u 8}=e^{-\lambda_{3} x} \sin \lambda_{4} x
\end{aligned}
$$

The wave contribution factors are as follows:

$$
\begin{aligned}
& B_{1}=\xi_{1} A_{1}, B_{2}=\xi_{1} A_{2}, B_{3}=\xi_{2} A_{3}, B_{4}=\xi_{2} A_{4} \\
& B_{5}=\xi_{3} A_{5}+\xi_{4} A_{6}, B_{6}=-\xi_{4} A_{5}+\xi_{3} A_{6} \\
& B_{7}=\xi_{3} A_{7}-\xi_{4} A_{8}, B_{8}=\xi_{4} A_{7}+\xi_{3} A_{8} \\
& C_{1}=\eta_{1} A_{1}, C_{2}=-\eta_{1} A_{2}, C_{3}=-\eta_{2} A_{3}, C_{4}=\eta_{2} A_{4} \\
& C_{5}=\eta_{3} A_{5}+\eta_{4} A_{6}, C_{6}=-\eta_{4} A_{5}+\eta_{3} A_{6} \\
& C_{7}=-\eta_{3} A_{7}+\eta_{4} A_{8}, C_{8}=-\eta_{4} A_{7}-\eta_{3} A_{8}
\end{aligned}
$$

And $n_{s}=8$ is the number of wave functions. In Eqs (4)-(6), $\lambda_{1}, \pm i \lambda_{2}, \pm\left(\lambda_{3} \pm i \lambda_{4}\right)$ are character roots to be determined which are given in [13]. $\xi_{1} \sim \xi_{4}$ and $\eta_{1} \sim \eta_{4}$ are constant coefficients related to character roots which are also given in [13].

According to [14], a set of wave functions describing the free vibration of annular circular plate are selected as follows:

$$
\begin{aligned}
& \psi_{w 1}=J_{n}\left(k_{p B} r\right), \psi_{w 2}=Y_{n}\left(k_{p B} r\right), \psi_{w 3}=I_{n}\left(k_{p B} r\right), \psi_{w 4}=K_{n}\left(k_{p B} r\right) \\
& \psi_{v 1}=n J_{n}\left(k_{p L} r\right) / r, \psi_{v 2}=\mathrm{d} J_{n}\left(k_{p T} r\right) / \mathrm{d} r, \psi_{v 3}=n Y_{n}\left(k_{p L} r\right) / r, \psi_{v 4}=\mathrm{d} Y_{n}\left(k_{p T} r\right) / \mathrm{dr} \\
& \psi_{u 1}=\mathrm{d} J_{n}\left(k_{p L} r\right) / \mathrm{d} r, \psi_{u 2}=n J_{n}\left(k_{p T} r\right) / r, \psi_{u 3}=\mathrm{d} Y_{n}\left(k_{p L} r\right) / \mathrm{d} r, \psi_{u 4}=n Y_{n}\left(k_{p T} r\right) / r
\end{aligned}
$$

The wave contribution factors are as follows:

$$
\begin{aligned}
& A_{1}=B_{1}=B_{1 n}, A_{2}=B_{2}=B_{2 n}, A_{3}=B_{3}=B_{3 n}, A_{4}=B_{4}=B_{4 n} \\
& C_{1}=A_{1 n}, C_{2}=A_{2 n}, C_{3}=A_{3 n}, C_{4}=A_{4 n}
\end{aligned}
$$

$n_{s}=8$ is the number of wave functions. $J_{n}, Y_{n}$ are Bessel functions of the first and the second kind respectively. $I_{n}, K_{n}$ are modified Bessel functions of the first and second kind respectively. $k_{p B}=\left(\rho_{p} \omega^{2} h_{p} / D_{p}\right)^{1 / 4}$ is the plate bending wave number, $k_{p L}=\omega\left[\rho_{p}\left(1-v_{p}^{2}\right) / E_{p}\right]^{1 / 2}, k_{p T}=\omega\left[2 \rho_{p}\left(1+v_{p}\right) / E_{p}\right]^{1 / 2}$ are the wave numbers for in-plane waves in the circular plate. The coefficients $A_{i, n}, B_{i, n}(i=1,2,3,4)$ are determined from the boundary conditions of the annular circular plates.

In contrast with the annular circular plates, the number of wave functions describing the motions of circular plates $n_{s}=4$ for the reason that $A_{3 n}=A_{4 n}=B_{3 n}=B_{4 n}=0$. 


\subsection{Matrix formed for calculating natural frequencies}

As shown in Fig. 3, the cylindrical shells with arbitrary boundary conditions have four displacement constraints $(u, v, w, \theta)$ and four force or moment constraints $(M, S, T, N)$, ie:

$$
\left.\left.\begin{array}{rl}
u & =0 \\
v & =0 \\
w & =0 \\
\theta & =0
\end{array}\right\} \text { and } \begin{array}{rl}
M & =0 \\
S & =0 \\
T & =0 \\
N & =0
\end{array}\right\}
$$

Where $\theta$ designates the twisting angle and $M, S, T, N$ designates bending moment, transverse shear, tangential shear and axial force per unit length of the cylindrical shell. Combination of these eight boundary conditions can present arbitrary boundary conditions. For example:

For clamped boundary conditions

$$
\left.\begin{array}{rl}
u & =0 \\
v & =0 \\
w & =0 \\
\theta & =0
\end{array}\right\}
$$

For shear diaphragm boundary conditions

$$
\left.\begin{array}{rl}
v & =0 \\
w & =0 \\
N & =0 \\
M & =0
\end{array}\right\}
$$

For free boundary conditions

$$
\left.\begin{array}{rl}
M & =0 \\
S & =0 \\
T & =0 \\
N & =0
\end{array}\right\}
$$

The cylindrical shell is divided into two segments by the ordinary ribs or intermediate large frame ribs or bulkheads as shown in Fig. 4 where continuity equations must be satisfied. The displacements of the two adjacent ends of the cylindrical shells must be equal, which can lead to the following relationship.

$$
w_{\Pi}^{L}=w_{\Pi}^{R}, v_{\Pi}^{L}=v_{\Pi}^{R}, u_{\Pi}^{L}=u_{\Pi}^{R}, \theta_{\Pi}^{L}=\theta_{\Pi}^{R}
$$

The superscripts $L$ and $R$ denote regions of the cylindrical shell to the left and right of the discontinuities under consideration.

The annular circular plate has one free edge at the inner radius where boundary conditions must be applied, ie:

$$
\left.N_{p x}\right|_{r=a_{1}}=\left.0 \quad N_{p r}\right|_{r=a_{1}}=\left.0 \quad N_{p \theta}\right|_{r=a_{1}}=\left.0 \quad M_{p}\right|_{r=a_{1}}=0
$$

At the outer radius of the annular circular plate which is shown in Fig. 4, the continuity conditions of displacements and forces between the cylindrical shells and the annular circular plates can be expressed as Eqs (15) and (16):

$$
\begin{aligned}
& \left.u_{p}\right|_{r=a}=w_{\Pi}^{R},\left.\quad v_{p}\right|_{r=a}=v_{\Pi}^{R},\left.\quad w_{p}\right|_{r=a}=u_{\Pi}^{R},\left.\quad \theta_{p}\right|_{r=a}=-\theta_{\Pi}^{R} \\
& \left\{\begin{array}{l}
N_{\Pi}^{L}=N_{p x}+N_{\Pi}^{R} \\
S_{\Pi}^{L}=N_{p r}+S_{\Pi}^{R} \\
T_{\Pi}^{L}=T_{\Pi}^{R}-N_{p \theta} \\
M_{\Pi}^{L}=M_{\Pi}^{R}-M_{p}
\end{array}\right.
\end{aligned}
$$




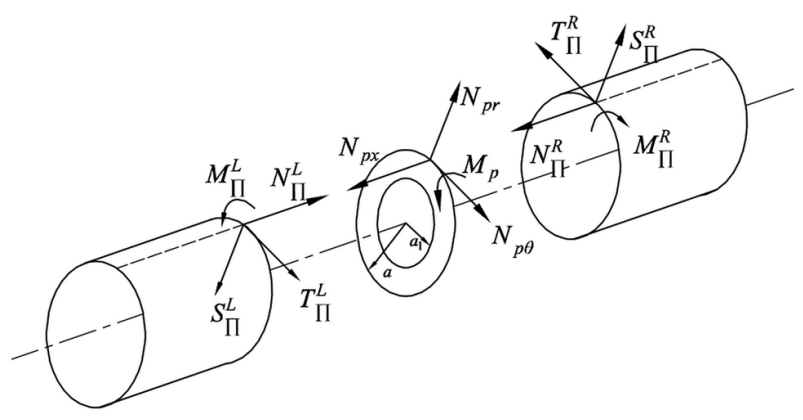

Fig. 4. Annular circular plate and interaction forces.
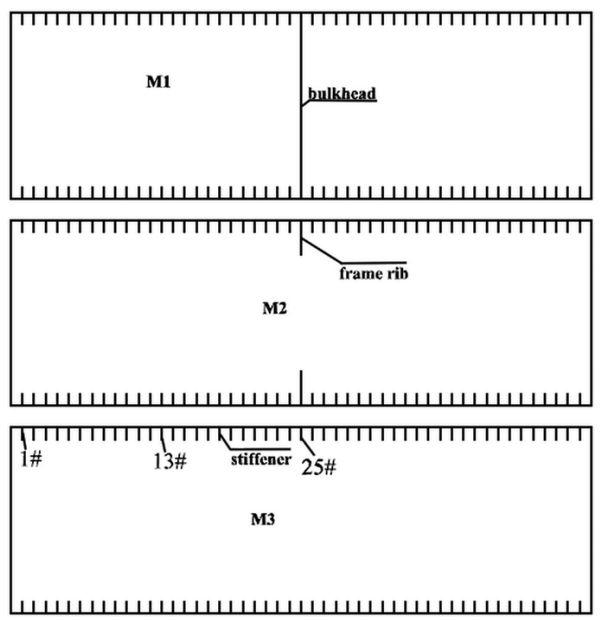

Fig. 5. Ring stiffened cylindrical shells with bulkhead/ intermediate large frame rib/all ordinary ribs.

For circular plate, only continuity conditions Eqs (15) and (16) must be satisfied for no boundary condition at the inner radius is applied because there are no free edges.

The above boundary conditions and the continuity conditions are arranged in matrix form for each circumferential number $n$. With $A_{i, n}, B_{i, n}(i=1,2,3,4)$ expressed by the coefficients $A_{1} \sim A_{8}$, the matrix is finally arranged as follows:

$$
[\mathrm{K}]\{\mathrm{A}\}=0
$$

$\{\mathrm{A}\}$ is the $8\left(N_{b}+N_{a}+1\right)$ or $8\left(N_{b}+N_{c}+1\right)$ unknown coefficient vector describing the motions of cylindrical shell and

$$
\mathrm{K}=\left[\begin{array}{ccccc}
{\left[\mathrm{B}_{1}(0)\right]} & & & \\
{\left[\mathrm{D}_{1}\left(b_{1}\right)\right]} & -\left[\mathrm{D}_{2}(0)\right] & & & \\
{\left[\mathrm{F}_{1}\left(b_{1}\right)\right]} & -\left[\mathrm{F}_{2}(0)\right] & & & \\
& {\left[\mathrm{D}_{2}\left(b_{2}\right)\right]} & -\left[\mathrm{D}_{3}(0)\right] & & \\
& {\left[\mathrm{F}_{2}\left(b_{2}\right)\right]} & -\left[\mathrm{F}_{3}(0)\right] & & \\
& \ldots & \ldots & \\
& & \ldots & & \\
& & {\left[\mathrm{D}_{N}\left(b_{N}\right)\right]} & -\left[\mathrm{D}_{N+1}(0)\right] \\
& & {\left[\mathrm{F}_{N}\left(b_{N}\right)\right]} & -\left[\mathrm{F}_{N+1}(0)\right] \\
& & & {\left[\mathrm{B}_{N+1}\left(b_{N+1}\right)\right]}
\end{array}\right]
$$

The $4 \times 8$ matrix blocks $\left[\mathrm{D}_{k}(0)\right]$ and $\left[\mathrm{D}_{k}\left(b_{k}\right)\right]$ can be obtained from Eq. (13). The $4 \times 8$ matrix blocks $\left[\mathrm{F}_{k}(0)\right]$ and $\left[\mathrm{F}_{k}\left(b_{k}\right)\right]$ can be obtained from Eqs (14)-(16) for the $k$ th substructure of cylindrical shell and two steps are needed to obtain $\left[\mathrm{F}_{k}(0)\right]$ and $\left[\mathrm{F}_{k}\left(b_{k}\right)\right]$. First, the relationship between the unknown vectors describing the displacement of the annular circular plates or the bulkheads $\left\{A_{k, 1 n}, \cdots, A_{k, 4 n}, B_{k, 1 n}, \cdots, B_{k, 4 n}\right\}$ and the unknown vectors describing the displacement of cylindrical shell $\left\{A_{k, 1}, \cdots, A_{k, 8}\right\}$ is deduced using Eqs (14) and (15). The $4 \times 8$ matrix blocks $\left[\mathrm{F}_{k}(0)\right]$ and $\left[\mathrm{F}_{k}\left(b_{k}\right)\right]$ are then obtained by substituting the relationship between $\left\{A_{k, 1 n}, \cdots, A_{k, 4 n}, B_{k, 1 n}, \cdots, B_{k, 4 n}\right\}$ and $\left\{A_{k, 1}, \cdots, A_{k, 8}\right\}$ into Eq. (16) which designates the force continuity conditions between the cylindrical shells and the outer radius of annular plates.

The initial and final blocks $\left[\mathrm{B}_{1}\right]$ and $\left[\mathrm{B}_{N+1}\right]$ are expressed in terms of displacement and/or forces, depending on the boundary conditions at each end of the cylindrical shell. Combination of eight boundary conditions in Eq. (9) can present arbitrary boundary conditions. Clamped, shear-diaphragm and free boundary conditions are considered here and are given by 
Table 1

Geometry dimensions and material properties of computation models

\begin{tabular}{lcc}
\hline Characteristic & Symbol & Geometry and material properties \\
\hline Radius & $a(\mathrm{~m})$ & 4.8 \\
Length & $l(\mathrm{~m})$ & 30 \\
Thickness of cylindrical shell & $h(\mathrm{~m})$ & 0.036 \\
Density & $\rho\left(\mathrm{kg} / \mathrm{m}^{3}\right)$ & 7800 \\
Young's modulus & $E(\mathrm{~Pa})$ & $2.1 \times 10^{11}$ \\
Poission's ratio & $\nu$ & 0.3 \\
Width of rectangular ordinary ribs & $b_{R}(\mathrm{~m})$ & 0.039 \\
Depth of rectangular ordinary ribs & $d_{R}(\mathrm{~m})$ & 0.3 \\
Spacing ratio of ribs & $l_{b}(\mathrm{~m})$ & 0.6 \\
Width of frame rib & $b_{f}(\mathrm{~m})$ & 0.054 \\
Depth of frame rib & $d_{f}(\mathrm{~m})$ & 0.99 \\
Thickness of bulkhead & $h_{p}(\mathrm{~m})$ & 0.018 \\
\hline
\end{tabular}

Table 2

FEM models with different meshes and substructure divisions of WBM models

\begin{tabular}{|c|c|c|c|c|c|c|c|c|}
\hline & \multicolumn{3}{|c|}{ Number of elements of model 1} & \multicolumn{3}{|c|}{ Number of elements of model 2} & \multirow{2}{*}{$\begin{array}{l}\text { Number of } \\
\text { substructures }\end{array}$} & \multirow{2}{*}{$\begin{array}{c}\text { Number of } \\
\text { substructures }\end{array}$} \\
\hline & Mesh 1 & Mesh 2 & Mesh 3 & Mesh 1 & Mesh 2 & Mesh 3 & & \\
\hline Cylindrical shell & $112 \times 100$ & $160 \times 150$ & $216 \times 200$ & $112 \times 100$ & $160 \times 150$ & $216 \times 200$ & 50 & 50 \\
\hline Stiffeners & $112 \times 1 \times 48$ & $160 \times 2 \times 48$ & $216 \times 2 \times 48$ & $112 \times 1 \times 48$ & $160 \times 2 \times 48$ & $216 \times 2 \times 48$ & 48 & 48 \\
\hline Frame ribs/bulkheads & 1000 & 2329 & 3733 & 672 & 960 & 1728 & 1 & 1 \\
\hline Total number & 17576 & 41689 & 67669 & 17248 & 40320 & 65664 & 99 & 99 \\
\hline
\end{tabular}

Clamped end (C):

$$
\left[\mathbf{B}_{k}(x)\right]_{4 \times 8}=\left[\begin{array}{l}
w_{k, 1}(x) \cdots w_{k, 8}(x) \\
v_{k, 1}(x) \cdots v_{k, 8}(x) \\
u_{k, 1}(x) \cdots u_{k, 8}(x) \\
\theta_{k, 1}(x) \cdots \theta_{k, 8}(x)
\end{array}\right], \quad k=1, N+1
$$

Shear-diaphragm (SD):

$$
\left[\mathbf{B}_{k}(x)\right]_{4 \times 8}=\left[\begin{array}{l}
w_{k, 1}(x) \cdots w_{k, 8}(x) \\
v_{k, 1}(x) \cdots v_{k, 8}(x) \\
N_{k, 1}(x) \cdots N_{k, 8}(x) \\
M_{k, 1}(x) \cdots M_{k, 8}(x)
\end{array}\right], \quad k=1, N+1
$$

Free end $(\mathrm{F})$ :

$$
\left[\mathrm{B}_{k}(x)\right]_{4 \times 8}=\left[\begin{array}{l}
S_{k, 1}(x) \cdots S_{k, 8}(x) \\
T_{k, 1}(x) \cdots T_{k, 8}(x) \\
N_{k, 1}(x) \cdots N_{k, 8}(x) \\
M_{k, 1}(x) \cdots M_{k, 8}(x)
\end{array}\right], \quad k=1, N+1
$$

$\Phi_{k, i}(x)(\Phi=u, v, w, \theta, M, S, T, N, i=1,2, \cdots, 8)$ designates the values of field variables at the position $x$ of the $k$ th segment of cylindrical shell. $A_{k, i}(i=1,2, \cdots, 8)$ designates the wave contribution factors of the $k$ th segment of cylindrical shell and $A_{k, i n}, B_{k, i n}(i=1,2,3,4)$ designates the wave contribution factors of the $k$ th circular annular plate. $b_{k}$ designates the length of the $k$ th segment of the cylindrical shell.

\subsection{Solution of the matrix and post-processing}

When analyzing the free vibration characteristics of ring-stiffened cylindrical shells with intermediate frame ribs and bulkheads, the value of the determinant of $[\mathrm{K}]$ is calculated for a sequence of trial values of frequency until a sign change is met, then the zero of the determinant is located by iterative interpolation. After a natural frequency has been accurately located, the solution of the homogeneous Eq. (17), normalized by taking the last wave function factor equals 1 , can be obtained which is used to calculate the vibration mode shape. 
Table 3

Comparison of natural frequencies calculated by FEM with different meshes $(\mathrm{Hz})$

\begin{tabular}{|c|c|c|c|c|c|c|c|}
\hline & \multirow{2}{*}{ Mode } & \multicolumn{3}{|c|}{ Model 1} & \multicolumn{3}{|c|}{ Model 2} \\
\hline & & Mesh 1 & Mesh 2 & Mesh 3 & Mesh 1 & Mesh 2 & Mesh 3 \\
\hline $\mathrm{n}=1$ & $\mathrm{~m}=1$ & 18.986 & 18.987 & 18.986 & 18.935 & 18.936 & 18.935 \\
\hline $\mathrm{n}=1$ & $\mathrm{~m}=2(\mathrm{a})$ & 51.923 & 51.925 & 91.921 & 51.923 & 51.925 & 51.92 \\
\hline $\mathrm{n}=2$ & $\begin{array}{l}\mathrm{m}=2(\mathrm{a}) \\
\mathrm{m}=2(\mathrm{~b})\end{array}$ & $\begin{array}{l}26.560 \\
25.010\end{array}$ & $\begin{array}{l}26.544 \\
25.055\end{array}$ & $\begin{array}{l}26.540 \\
25.077\end{array}$ & $\begin{array}{c}26.559 \\
-\end{array}$ & $\begin{array}{c}26.544 \\
-\end{array}$ & $\begin{array}{c}26.54 \\
-\end{array}$ \\
\hline $\mathrm{n}=3$ & $\begin{array}{l}\mathrm{m}=2(\mathrm{a}) \\
\mathrm{m}=2(\mathrm{~b})\end{array}$ & $\begin{array}{l}28.999 \\
29.954\end{array}$ & $\begin{array}{l}28.909 \\
29.885\end{array}$ & $\begin{array}{l}28.893 \\
29.876\end{array}$ & $\begin{array}{l}29.002 \\
29.901\end{array}$ & $\begin{array}{l}28.911 \\
29.816\end{array}$ & $\begin{array}{l}28.895 \\
29.8\end{array}$ \\
\hline $\mathrm{n}=4$ & $\begin{array}{l}\mathrm{m}=2(\mathrm{a}) \\
\mathrm{m}=2(\mathrm{~b})\end{array}$ & $\begin{array}{l}48.626 \\
48.921\end{array}$ & $\begin{array}{l}48.390 \\
48.692\end{array}$ & $\begin{array}{l}48.340 \\
48.643\end{array}$ & $\begin{array}{l}48.614 \\
48.957\end{array}$ & $\begin{array}{l}48.381 \\
48.726\end{array}$ & $\begin{array}{l}48.331 \\
48.676\end{array}$ \\
\hline $\mathrm{n}=5$ & $\begin{array}{l}\mathrm{m}=2(\mathrm{a}) \\
\mathrm{m}=2(\mathrm{~b})\end{array}$ & $\begin{array}{l}76.189 \\
76.262\end{array}$ & $\begin{array}{l}75.704 \\
75.777\end{array}$ & $\begin{array}{l}75.623 \\
75.658\end{array}$ & $\begin{array}{l}76.193 \\
76.272\end{array}$ & $\begin{array}{l}75.705 \\
75.786\end{array}$ & $\begin{array}{l}75.586 \\
75.667 \\
\end{array}$ \\
\hline
\end{tabular}

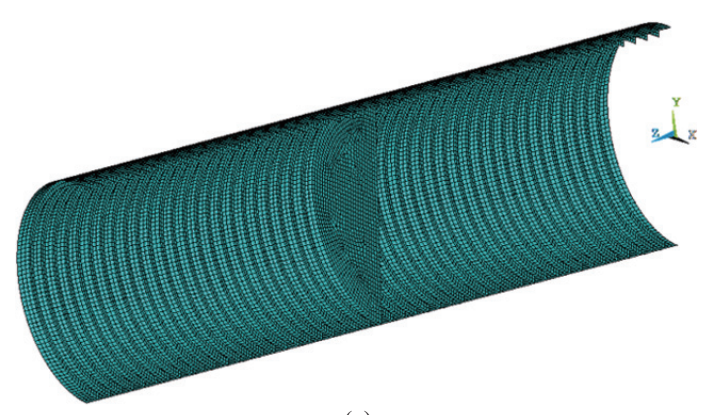

(a)

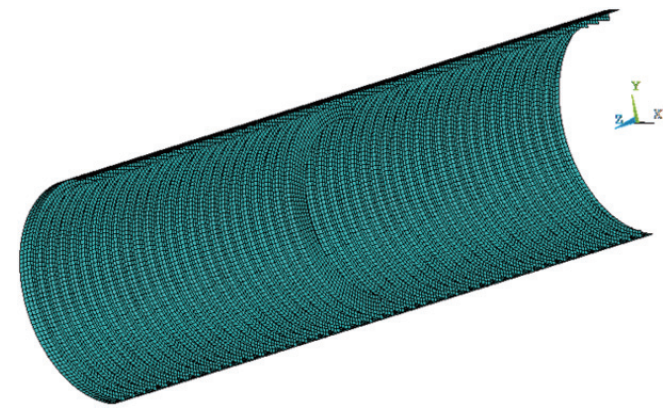

(b)

Fig. 6. FEM models of the two computation models with mesh 2 (a) Model M1 (b) Model M2.

\section{Results and discussions}

\subsection{Validity of WBM model for cylindrical shells with intermediate large frame ribs or bulkheads}

The WBM model is first developed to calculate the natural frequencies of ring-stiffened cylindrical shells with intermediate large frame ribs and bulkheads for C-C, SD-SD, F-F boundary conditions. Numerical results are compared with FEM results to show the validity of WBM model. Two computation models are considered here as shown in Fig. 5, one is with single bulkhead which is denoted as model M1 and the other is with single intermediate frame rib which is denoted as model M2. Both models are even spaced ring-stiffened cylindrical shells whose geometry and material properties are listed in Table 1. The cylindrical shells, the ordinary ribs, the intermediate large frame rib and the bulkhead have the same material. Both the frame rib and the bulkhead are in the middle section of the cylindrical shell.

The finite element package ANSYS is used to calculate natural frequencies of model M1 and M2. In order to ensure the convergence of results calculated by FEM, three different kinds of meshes shown in Table 2 are used to calculate natural frequencies of model M1 and M2 for SD-SD boundary conditions with the results shown in Table 3. Shell63 element is adopted to model the cylindrical shells, the ordinary ribs, the frame rib and the bulkhead. The two numbers in each cell in the third row of Table 2 denote the number of elements in the circumferential and axial direction respectively and the three numbers in each cell in the fourth row denote the number of elements in the circumferential, radial and axial direction respectively. Due to the symmetry about the middle longitudinal cross section, half parts of the two FEM models are shown in Fig. 6. $m, n$ in Table 3 denote the axial half wave number and the circumferential wave number respectively. $\mathrm{m}=2$ (a) and $\mathrm{m}=2$ (b) denote two different vibration modes which are shown in Figs 7-12. Some frequencies are missing in Table 3 for the reason that there are no corresponding vibration modes. Mesh 2 which can achieve both high computation efficiency and adequate converged results is used in the following analysis. 


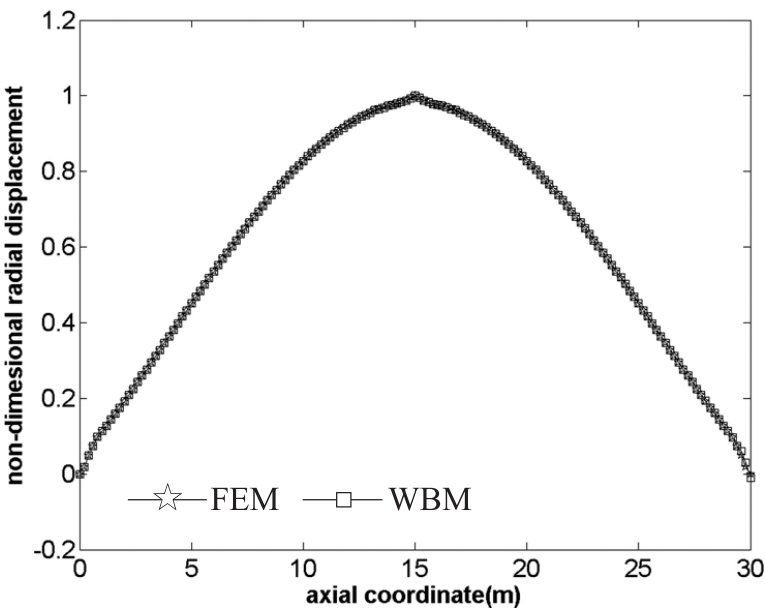

(a) $\mathrm{n}=1, \mathrm{~m}=1$

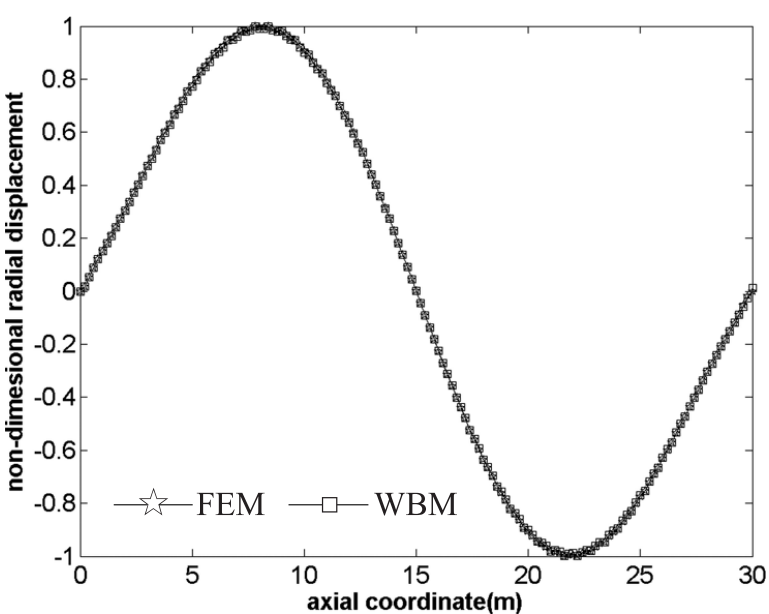

(b) $\mathrm{n}=3, \mathrm{~m}=2$ (a)

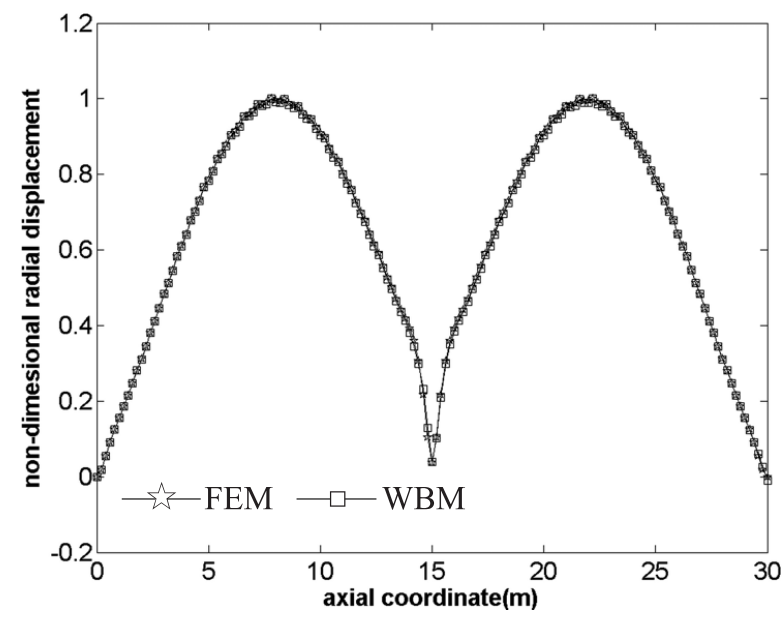

(c) $\mathrm{n}=3, \mathrm{~m}=2$ (b)

Fig. 7. Comparison of vibration mode shapes of model M1 calculated by FEM and WBM for C-C boundary condition.

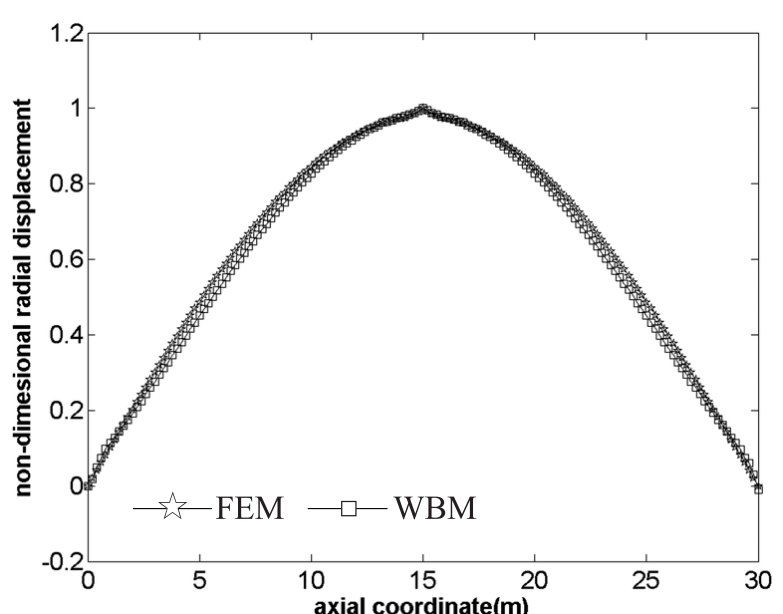

(a) $\mathrm{n}=1, \mathrm{~m}=1$

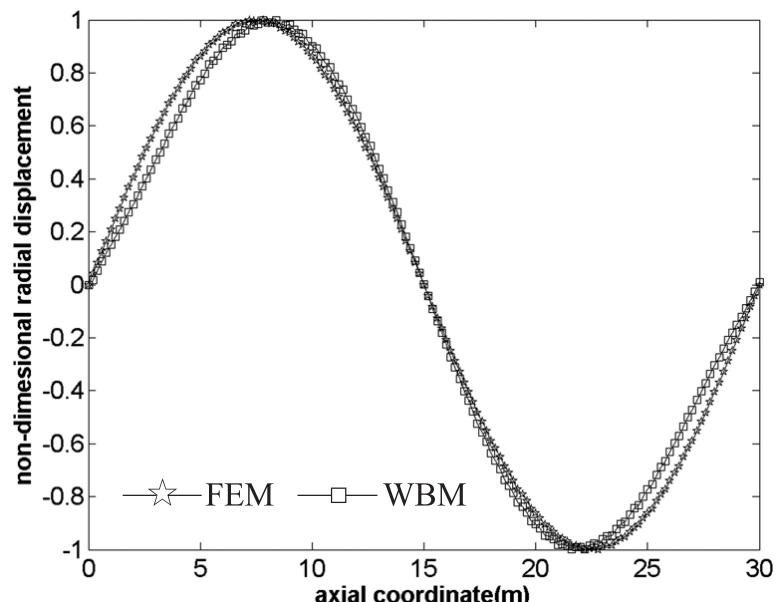

(b) $\mathrm{n}=3, \mathrm{~m}=2$ (a)

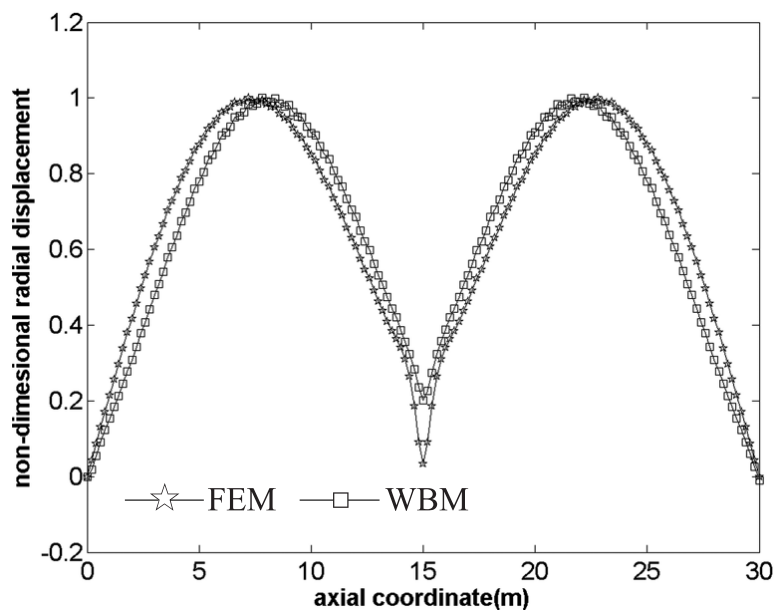

(c) $\mathrm{n}=3, \mathrm{~m}=2$ (b)

Fig. 8. Comparison of vibration mode shapes of model M1 calculated by FEM and WBM for SD-SD boundary condition. 


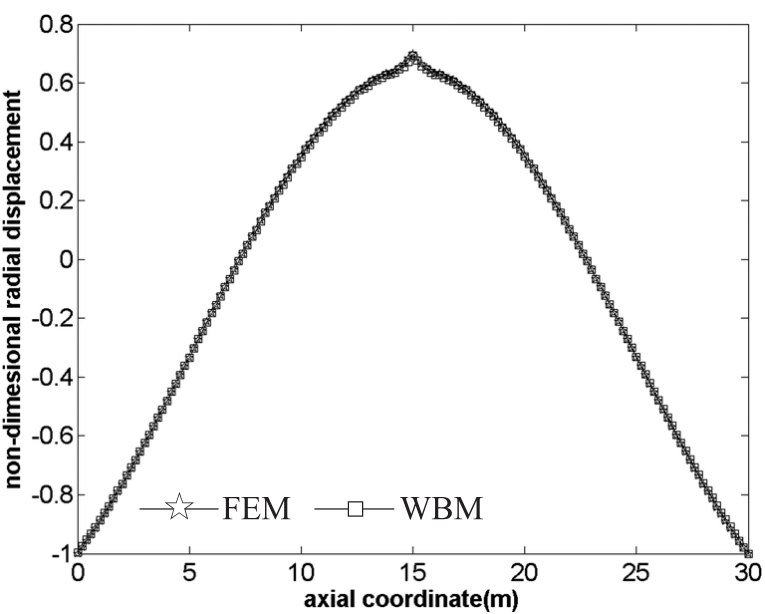

(a) $\mathrm{n}=1, \mathrm{~m}=1$

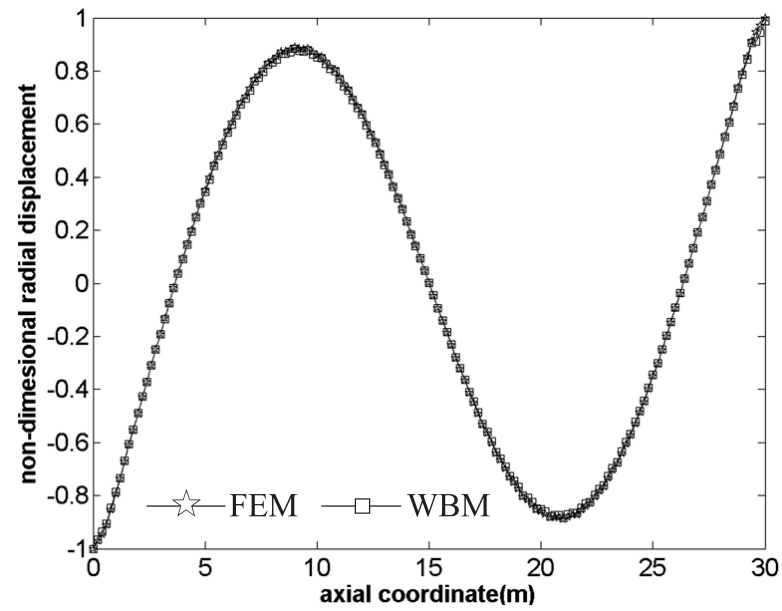

(b) $\mathrm{n}=3, \mathrm{~m}=2$ (a)

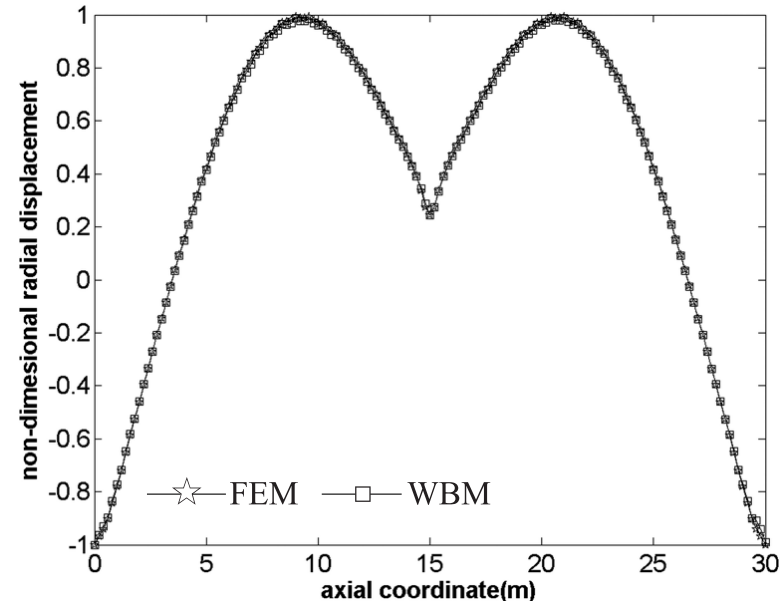

(c) $\mathrm{n}=3, \mathrm{~m}=2$ (b)

Fig. 9. Comparison of vibration mode shapes of model M1 calculated by FEM and WBM for F-F boundary condition.

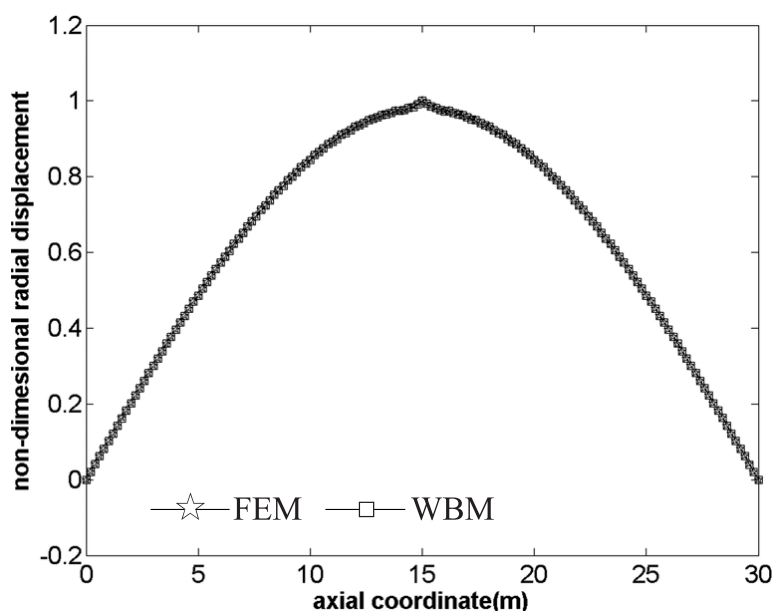

(a) $\mathrm{n}=1, \mathrm{~m}=1$

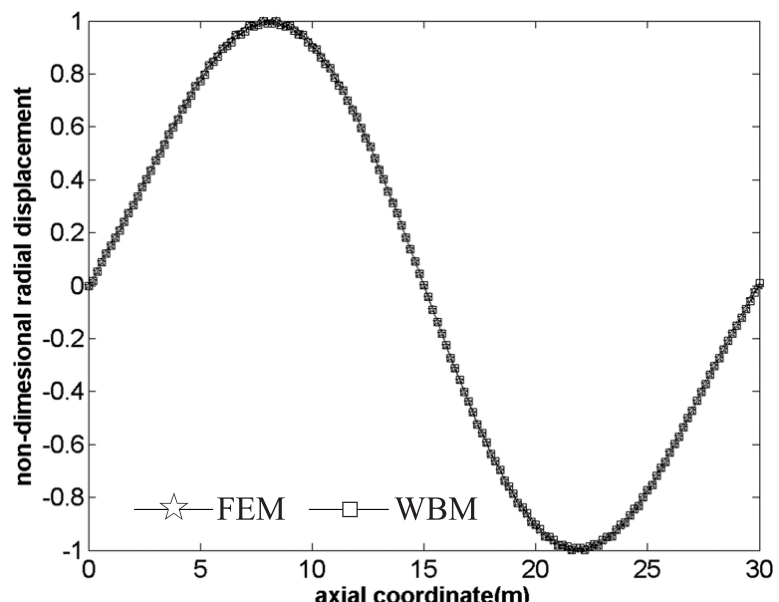

(b) $\mathrm{n}=3, \mathrm{~m}=2$ (a)

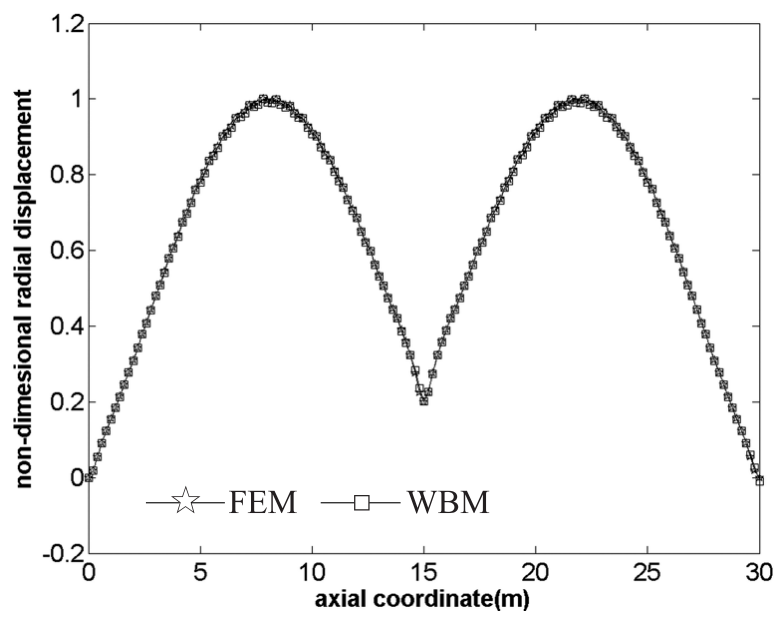

(c) $\mathrm{n}=3, \mathrm{~m}=2$ (b)

Fig. 10. Comparison of vibration mode shapes of model M2 calculated by FEM and WBM for C-C boundary condition. 


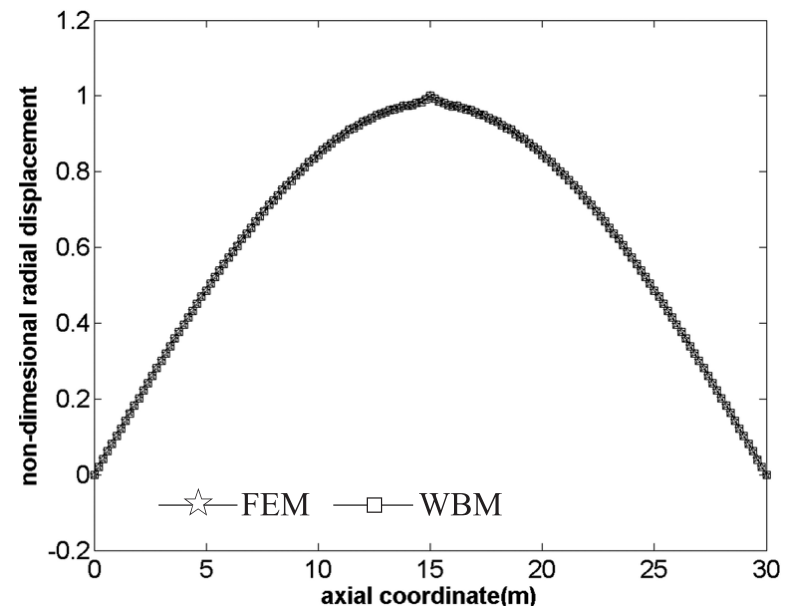

(a) $\mathrm{n}=1, \mathrm{~m}=1$

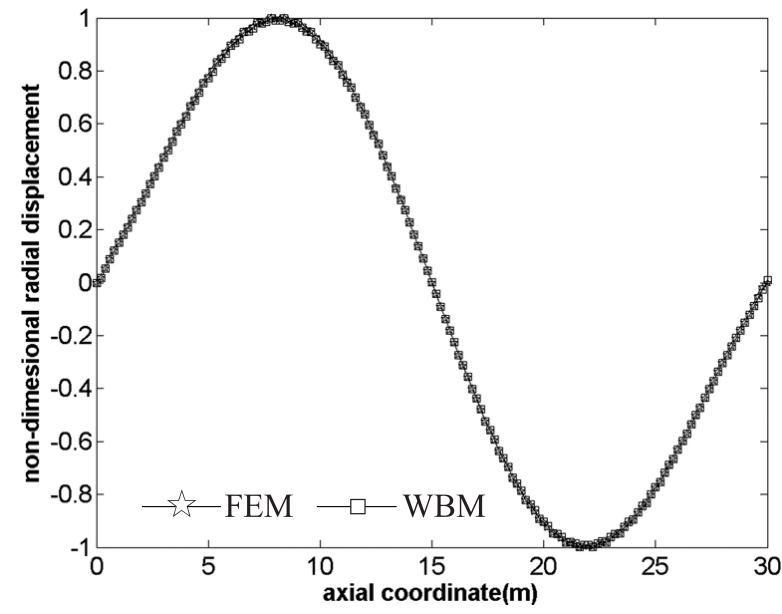

(b) $\mathrm{n}=3, \mathrm{~m}=2$ (a)

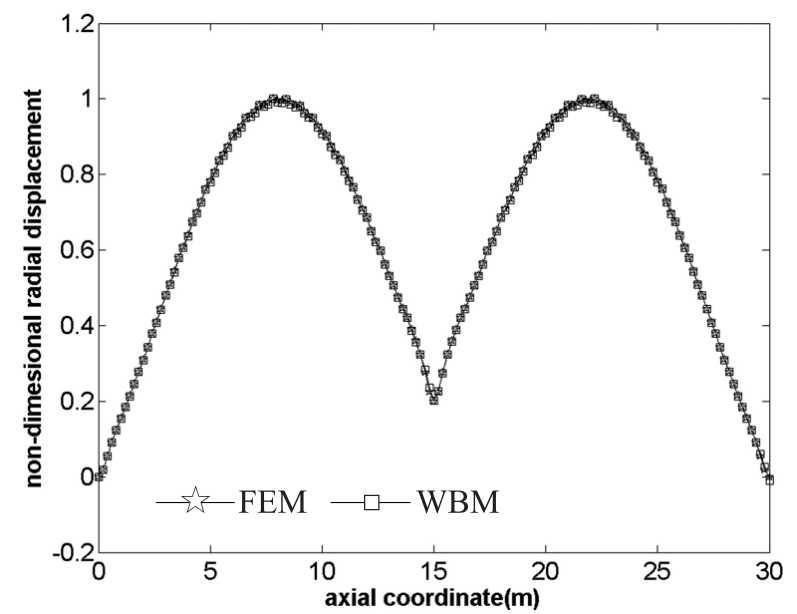

(c) $\mathrm{n}=3, \mathrm{~m}=2(\mathrm{~b})$

Fig. 11. Comparison of vibration mode shapes of model M2 calculated by FEM and WBM for SD-SD boundary condition.

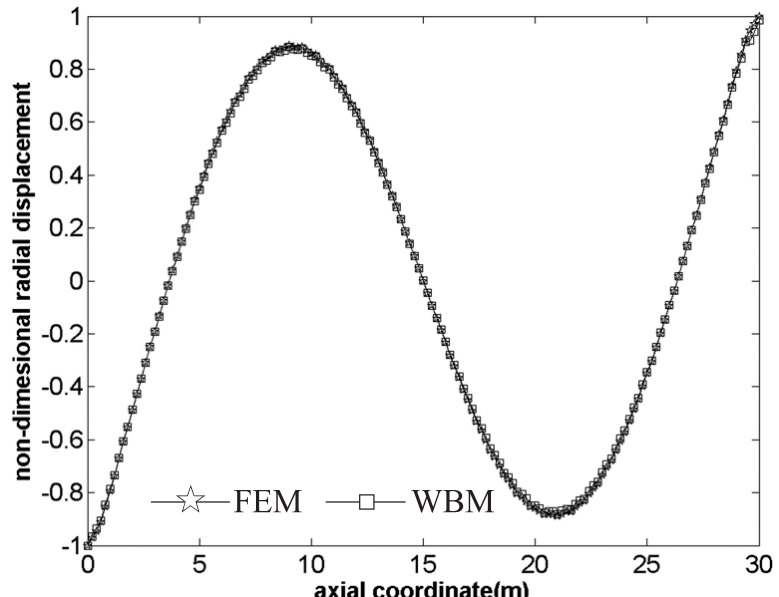

(a) $\mathrm{n}=1, \mathrm{~m}=1$

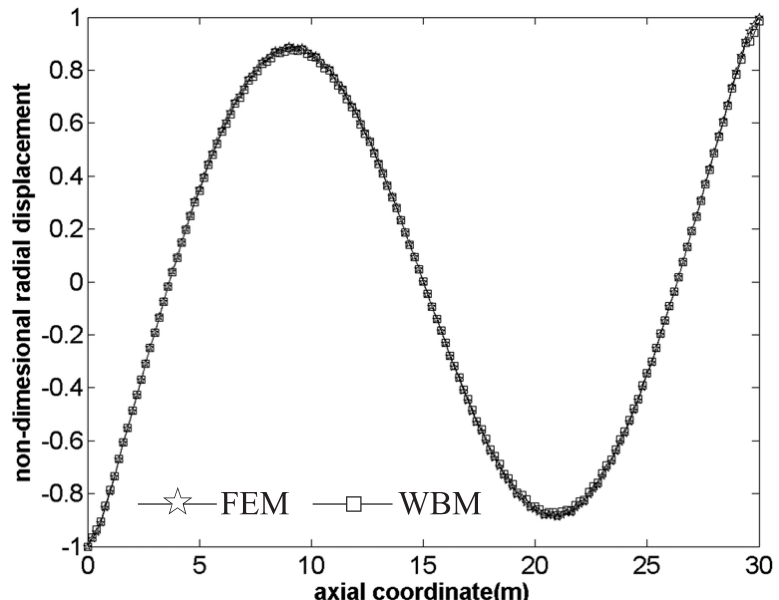

(b) $\mathrm{n}=3, \mathrm{~m}=2$ (a)

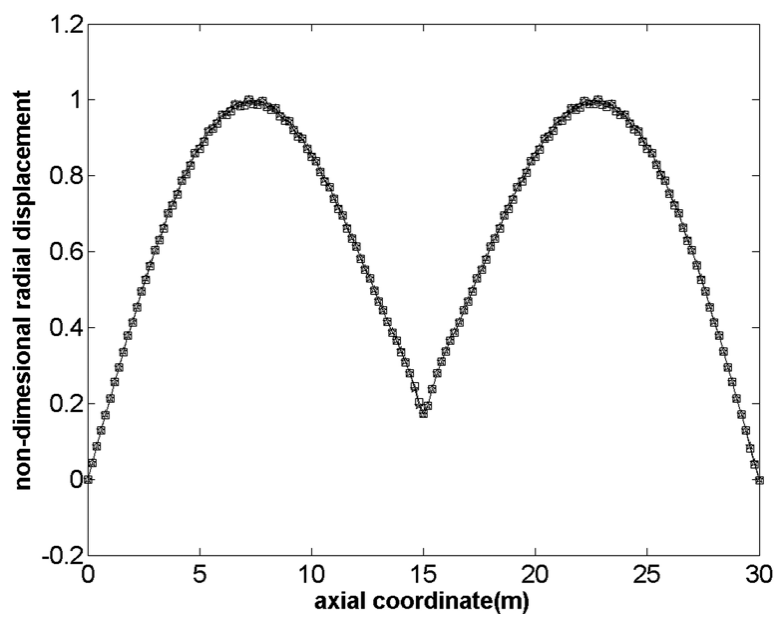

(c) $\mathrm{n}=3, \mathrm{~m}=2$ (b)

Fig. 12. Comparison of vibration mode shapes of model M2 calculated by FEM and WBM for F-F boundary condition. 
Table 4

Comparison of natural frequencies of model M1 calculated by FEM and WBM

\begin{tabular}{|c|c|c|c|c|c|c|c|c|c|c|}
\hline & \multirow{2}{*}{ Mode } & \multicolumn{3}{|c|}{$\mathrm{C}-\mathrm{C}(\mathrm{Hz})$} & \multicolumn{3}{|c|}{ SD-SD(Hz) } & \multicolumn{3}{|c|}{$\mathrm{F}-\mathrm{F}(\mathrm{Hz})$} \\
\hline & & FEM & WBM & Difference & FEM & WBM & Difference & FEM & WBM & Difference \\
\hline $\mathrm{n}=1$ & $\mathrm{~m}=1$ & 26.514 & 26.513 & $0.00 \%$ & 18.987 & 18.989 & $0.01 \%$ & 38.397 & 38.399 & $0.01 \%$ \\
\hline $\mathrm{n}=1$ & $\mathrm{~m}=2(\mathrm{a})$ & 53.773 & 53.769 & $0.01 \%$ & 51.925 & 51.922 & $0.01 \%$ & 66.785 & 66.782 & $0.00 \%$ \\
\hline $\mathrm{n}=2$ & $\begin{array}{l}\mathrm{m}=2(\mathrm{a}) \\
\mathrm{m}=2(\mathrm{~b})\end{array}$ & $\begin{array}{l}30.516 \\
28.734\end{array}$ & $\begin{array}{l}30.518 \\
28.800\end{array}$ & $\begin{array}{l}0.01 \% \\
0.23 \%\end{array}$ & $\begin{array}{l}26.544 \\
25.055\end{array}$ & $\begin{array}{l}26.549 \\
25.119\end{array}$ & $\begin{array}{l}0.02 \% \\
0.26 \%\end{array}$ & $\begin{array}{l}37.668 \\
31.272\end{array}$ & $\begin{array}{l}37.673 \\
31.361\end{array}$ & $\begin{array}{l}0.01 \% \\
0.28 \%\end{array}$ \\
\hline $\mathrm{n}=3$ & $\begin{array}{l}\mathrm{m}=2(\mathrm{a}) \\
\mathrm{m}=2(\mathrm{~b})\end{array}$ & $\begin{array}{l}30.560 \\
31.507\end{array}$ & $\begin{array}{l}30.535 \\
31.503\end{array}$ & $\begin{array}{l}0.08 \% \\
0.01 \%\end{array}$ & $\begin{array}{l}28.909 \\
29.885\end{array}$ & $\begin{array}{l}28.883 \\
29.876\end{array}$ & $\begin{array}{l}0.09 \% \\
0.03 \%\end{array}$ & $\begin{array}{l}32.114 \\
32.615\end{array}$ & $\begin{array}{l}32.100 \\
32.631\end{array}$ & $\begin{array}{l}0.04 \% \\
0.05 \%\end{array}$ \\
\hline $\mathrm{n}=4$ & $\begin{array}{l}\mathrm{m}=2(\mathrm{a}) \\
\mathrm{m}=2(\mathrm{~b})\end{array}$ & $\begin{array}{l}48.787 \\
49.132\end{array}$ & $\begin{array}{l}48.648 \\
49.000\end{array}$ & $\begin{array}{l}0.28 \% \\
0.27 \%\end{array}$ & $\begin{array}{l}48.390 \\
48.692\end{array}$ & $\begin{array}{l}48.251 \\
48.557\end{array}$ & $\begin{array}{l}0.29 \% \\
0.28 \%\end{array}$ & $\begin{array}{l}48.849 \\
49.225\end{array}$ & $\begin{array}{l}48.716 \\
49.100\end{array}$ & $\begin{array}{l}0.27 \% \\
0.25 \%\end{array}$ \\
\hline $\mathrm{n}=5$ & $\begin{array}{l}\mathrm{m}=2(\mathrm{a}) \\
\mathrm{m}=2(\mathrm{~b})\end{array}$ & $\begin{array}{l}75.804 \\
75.889\end{array}$ & $\begin{array}{l}75.442 \\
75.535\end{array}$ & $\begin{array}{l}0.48 \% \\
0.47 \%\end{array}$ & $\begin{array}{l}75.704 \\
75.777\end{array}$ & $\begin{array}{l}75.342 \\
75.422\end{array}$ & $\begin{array}{l}0.48 \% \\
0.47 \%\end{array}$ & $\begin{array}{l}75.782 \\
75.868\end{array}$ & $\begin{array}{l}75.420 \\
75.515\end{array}$ & $\begin{array}{l}0.48 \% \\
0.47 \%\end{array}$ \\
\hline
\end{tabular}

Table 5

Comparison of natural frequencies of model M2 calculated by FEM and WBM

\begin{tabular}{|c|c|c|c|c|c|c|c|c|c|c|}
\hline & \multirow{2}{*}{ Mode } & \multicolumn{3}{|c|}{$\mathrm{C}-\mathrm{C}(\mathrm{Hz})$} & \multicolumn{3}{|c|}{ SD-SD(Hz) } & \multicolumn{3}{|c|}{$\mathrm{F}-\mathrm{F}(\mathrm{Hz})$} \\
\hline & & FEM & WBM & Difference & FEM & WBM & Difference & FEM & WBM & Difference \\
\hline $\mathrm{n}=1$ & $\mathrm{~m}=1$ & 26.444 & 26.443 & $0.00 \%$ & 18.936 & 18.938 & $0.01 \%$ & 38.333 & 38.335 & $0.01 \%$ \\
\hline $\mathrm{n}=1$ & $\mathrm{~m}=2(\mathrm{a})$ & 53.784 & 53.780 & $0.01 \%$ & 51.925 & 51.921 & $0.01 \%$ & 66.803 & 66.800 & $0.00 \%$ \\
\hline $\mathrm{n}=2$ & $\mathrm{~m}=2(\mathrm{a})$ & 30.511 & 30.513 & $0.01 \%$ & 26.544 & 26.549 & $0.02 \%$ & 37.662 & 37.668 & $0.02 \%$ \\
\hline $\mathrm{n}=3$ & $\begin{array}{l}\mathrm{m}=2(\mathrm{a}) \\
\mathrm{m}=2(\mathrm{~b})\end{array}$ & $\begin{array}{l}30.537 \\
31.422\end{array}$ & $\begin{array}{l}30.537 \\
31.396\end{array}$ & $\begin{array}{l}0.00 \% \\
0.08 \%\end{array}$ & $\begin{array}{l}28.911 \\
29.816\end{array}$ & $\begin{array}{l}28.886 \\
29.789\end{array}$ & $\begin{array}{l}0.09 \% \\
0.09 \%\end{array}$ & $\begin{array}{l}32.116 \\
32.518\end{array}$ & $\begin{array}{l}32.103 \\
32.501\end{array}$ & $\begin{array}{l}0.04 \% \\
0.05 \%\end{array}$ \\
\hline $\mathrm{n}=4$ & $\begin{array}{l}\mathrm{m}=2(\mathrm{a}) \\
\mathrm{m}=2(\mathrm{~b})\end{array}$ & $\begin{array}{l}48.771 \\
49.179\end{array}$ & $\begin{array}{l}48.634 \\
49.044\end{array}$ & $\begin{array}{l}0.28 \% \\
0.27 \%\end{array}$ & $\begin{array}{l}48.381 \\
48.726\end{array}$ & $\begin{array}{l}48.243 \\
48.588\end{array}$ & $\begin{array}{l}0.29 \% \\
0.28 \%\end{array}$ & $\begin{array}{l}48.829 \\
49.284\end{array}$ & $\begin{array}{l}48.698 \\
49.155\end{array}$ & $\begin{array}{l}0.27 \% \\
0.26 \%\end{array}$ \\
\hline $\mathrm{n}=5$ & $\begin{array}{l}\mathrm{m}=2(\mathrm{a}) \\
\mathrm{m}=2(\mathrm{~b})\end{array}$ & $\begin{array}{l}75.807 \\
75.900\end{array}$ & $\begin{array}{l}75.452 \\
75.546\end{array}$ & $\begin{array}{l}0.47 \% \\
0.47 \%\end{array}$ & $\begin{array}{l}75.705 \\
75.786\end{array}$ & $\begin{array}{l}75.349 \\
75.431\end{array}$ & $\begin{array}{l}0.47 \% \\
0.47 \%\end{array}$ & $\begin{array}{l}75.785 \\
75.880\end{array}$ & $\begin{array}{l}75.430 \\
75.526\end{array}$ & $\begin{array}{l}0.47 \% \\
0.47 \%\end{array}$ \\
\hline
\end{tabular}

The WBM model is divided into different substructures which are also shown in Table 2, the vibration field of which is expanded by analytical solutions of corresponding structure type. From Table 2 we can see that the number of substructures in WBM model is much less than the number of substructures used in FEM models.

Tables 4 and 5 show the comparison of natural frequencies of model M1 and model M2 between WBM results and FEM results. As we can see from the tables, the results are in good agreement which show the validity of WBM model. Figures 7-12 shows the comparison of radial displacements along the axial direction of the cylindrical shell with the maximum displacement scaled to unit for C-C, SD-SD and F-F boundary conditions and also good agreement has been achieved. From above figures we can see that the cylindrical shell vibrates as a whole for $\mathrm{m}=2$ (a) with the radial displacement along the axial direction of the cylindrical shell showing a standard sine curve form, or from another point of view, we can assume that the cylindrical shell is divided into two cabins by the intermediate large frame rib/bulkhead with each part vibrating separately as $\mathrm{m}=1$ with opposite phases. This pattern of vibration is called "no cabin subdivision vibration modes" in the following analysis. Apparently for $\mathrm{m}=2(\mathrm{~b})$, the cylindrical shell is divided into two cabins by the intermediate frame rib/bulkhead with each part vibrating separately as $\mathrm{m}=1$ in the same phase and this pattern of vibration is called "cabin subdivision vibration modes" in the following analysis.

\subsection{Free vibration characteristics of ring stiffened cylindrical shells with intermediate frame ribs}

Numerical calculations have been performed here to study the effects of the size, number and distributions of intermediate frame ribs on the free vibration characteristics of ring stiffened cylindrical shells with C-C, SD-SD and F-F boundary conditions.

Table 6 shows comparison of natural frequencies of ring stiffened cylindrical shells with single bulkhead/ intermediate frame rib/all ordinary ribs which are shown in Fig. 5 denoted as model M1 M3. We can see from Table 6 that the three models have nearly the same natural frequencies of "no cabin subdivision vibration modes" for $\mathrm{m}=2$ 
Table 6

Comparison of natural frequencies of model M1, M2 and M3

\begin{tabular}{|c|c|c|c|c|c|c|c|c|c|c|}
\hline & \multirow{2}{*}{ Mode } & \multicolumn{3}{|c|}{$\mathrm{C}-\mathrm{C}(\mathrm{Hz})$} & \multicolumn{3}{|c|}{$\mathrm{SD}-\mathrm{SD}(\mathrm{Hz})$} & \multicolumn{3}{|c|}{$\mathrm{F}-\mathrm{F}(\mathrm{Hz})$} \\
\hline & & M1 & M2 & M3 & M1 & M2 & M3 & M1 & M2 & M3 \\
\hline $\mathrm{n}=1$ & $\mathrm{~m}=1$ & 26.513 & 26.443 & 27.061 & 18.989 & 18.938 & 19.340 & 38.399 & 38.335 & 38.908 \\
\hline $\mathrm{n}=1$ & $\mathrm{~m}=2(\mathrm{a})$ & 53.769 & 53.780 & 53.768 & 51.922 & 51.921 & 51.919 & 66.782 & 66.800 & 66.768 \\
\hline \multirow[t]{2}{*}{$\mathrm{n}=2$} & $\mathrm{~m}=2(\mathrm{a})$ & 30.518 & 30.513 & 30.514 & 26.549 & 26.549 & 26.548 & 37.673 & 37.668 & 37.673 \\
\hline & $\mathrm{m}=2(\mathrm{~b})$ & 28.800 & - & - & 25.119 & - & - & 31.361 & - & - \\
\hline \multirow[t]{2}{*}{$\mathrm{n}=3$} & $m=2(a)$ & 30.535 & 30.537 & 30.534 & 28.883 & 28.886 & 28.883 & 32.100 & 32.103 & 32.100 \\
\hline & $m=2(b)$ & 31.503 & 31.396 & - & 29.876 & 29.789 & - & 32.631 & 32.501 & - \\
\hline \multirow[t]{2}{*}{$\mathrm{n}=4$} & $\mathrm{~m}=2(\mathrm{a})$ & 48.648 & 48.634 & 48.647 & 48.251 & 48.243 & 48.250 & 48.716 & 48.698 & 48.716 \\
\hline & $\mathrm{m}=2(\mathrm{~b})$ & 49.000 & 49.044 & - & 48.557 & 48.588 & - & 49.100 & 49.155 & - \\
\hline \multirow[t]{2}{*}{$\mathrm{n}=5$} & $\mathrm{~m}=2(\mathrm{a})$ & 75.442 & 75.452 & 75.444 & 75.342 & 75.349 & 75.343 & 75.420 & 75.430 & 75.423 \\
\hline & $m=2(b)$ & 75.535 & 75.546 & - & 75.422 & 75.431 & - & 75.515 & 75.526 & - \\
\hline
\end{tabular}

from which we can make a conclusion that the intermediate frame rib and the bulkhead have little effect on natural frequencies of "no cabin subdivision vibration modes". Compared with model M3, "cabin subdivision vibration modes" appear in model M1 and model M2, and natural frequencies of "cabin subdivision vibration modes" are a little larger than corresponding "no cabin subdivision vibration mode" frequencies except $\mathrm{n}=2, \mathrm{~m}=2$ of model M1. The difference between model M1 and M2 is that “cabin subdivision vibration modes" don't appear until n = 3, $\mathrm{m}=2$ for model M2 while they always exist for model M1.

For $\mathrm{n}=1, \mathrm{~m}=1$, which is beam mode, the natural frequencies of model M3 is a little larger than model M1 and model M2 while the beam mode frequencies of M1 and M2 are nearly the same. This phenomenon can be explained by energy theory which has been presented in [19]. In beam mode, the shape of stiffeners, bulkheads and intermediate frame ribs remain circular and their strain energy does not affect the total energy of the system and only their kinetic energy contributes in the total energy, therefore decrement of mass distribution in the midsection of the shell reduces the kinetic energy and raises the beam mode natural frequency.

From the above analysis we can see that not all the intermediate frame ribs have "cabin subdivision" effects. What is the critical size of intermediate frame ribs in order to achieve "cabin subdivision vibration modes"? In order to answer this question, natural frequencies and vibration mode shapes of cylindrical shells with intermediate frame ribs with different widths and depths are calculated. The depth of the frame rib increase from $d_{f}=0.3 \mathrm{~m}$ to $d_{f}=3 \mathrm{~m}$ and the width of frame rib increase from $b_{f}=0.018 \mathrm{~m}$ to $b_{f}=0.078 \mathrm{~m}$. Both "no cabin subdivision vibration mode" frequencies and "cabin subdivision vibration mode" frequencies are calculated. The "cabin subdivision vibration mode" shapes are also calculated shown in Fig. 13.

The variation of beam mode frequencies and "no cabin subdivision vibration mode" frequencies with the size of intermediate frame rib can be observed from the numerical results that increment of the width or the depth of intermediate frame rib both leads to decrement of the beam mode frequencies which is mainly due to increment of mass distribution in the midsection as explained above. "No cabin subdivision vibration mode" frequencies are all nearly the same for different sizes of intermediate frame rib from which a conclusion can be made that the size of intermediate frame rib has little effect on "no cabin subdivision vibration mode" frequencies.

The variation of "cabin subdivision vibration mode" frequencies with the size of intermediate frame rib can also be observed. For C-C boundary conditions, the critical sizes of the frame rib are respectively: $(1) d_{f}=1.5 \mathrm{~m}$, $b_{f}=0.018 \mathrm{~m}$ for $\mathrm{n}=2, \mathrm{~m}=2(\mathrm{~b}) ;(2) d_{f}=0.5 \mathrm{~m}, b_{f}=0.038 \mathrm{~m}$ for $\mathrm{n}=3, \mathrm{~m}=2(\mathrm{~b}) ;(3) d_{f}=0.4 \mathrm{~m}$, $b_{f}=0.038 \mathrm{~m}$ for $\mathrm{n}=4, \mathrm{~m}=2(\mathrm{~b}) ;(4) d_{f}=0.3 \mathrm{~m}, b_{f}=0.048 \mathrm{~m}$ for $\mathrm{n}=5, \mathrm{~m}=2(\mathrm{~b})$. The critical depth is larger at lower circumferential wave number which means that it is harder for "cabin subdivision vibration modes" to appear at lower circumferential wave number and larger size of intermediate frame rib is required. Increment of the depth or the width of the frame rib both can lead to increment of "cabin subdivision vibration mode" frequencies. "Cabin subdivision vibration mode" frequencies are not always larger than corresponding "no cabin subdivision vibration mode" frequencies especially for $\mathrm{n}=2, \mathrm{~m}=2(\mathrm{~b})$ for which case only when the intermediate frame rib gets quite a large depth and width can the "cabin subdivision vibration mode" frequencies be larger than corresponding "no cabin subdivision vibration mode" frequencies. For higher wave number $\mathrm{n}=5$, most of the "cabin subdivision vibration mode" frequencies are larger than corresponding "no cabin subdivision vibration mode" frequencies even at a smaller size of frame rib. 


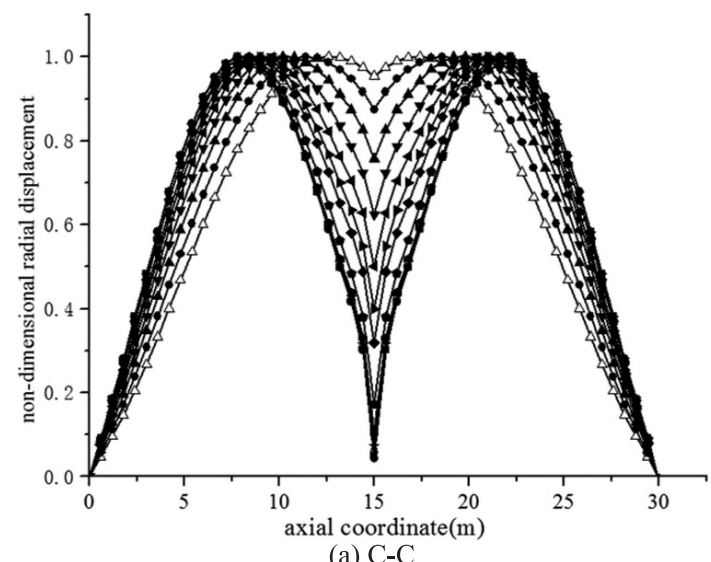

(a) $\mathrm{C}-\mathrm{C}$

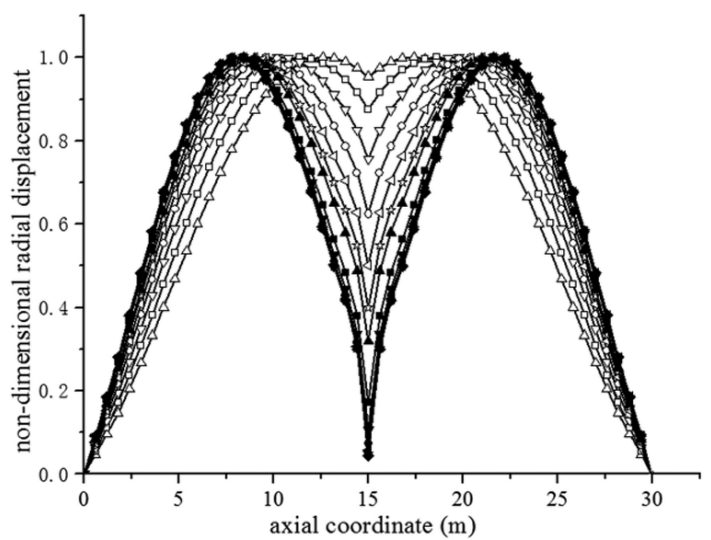

(b) SD-SD

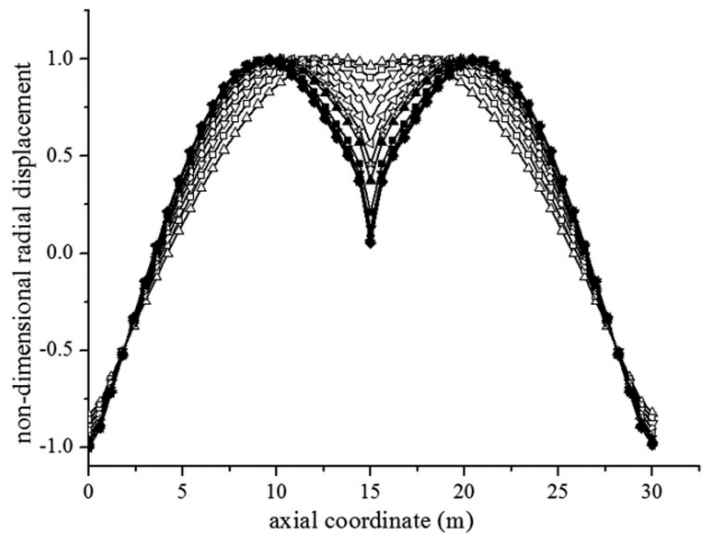

(c) F-F

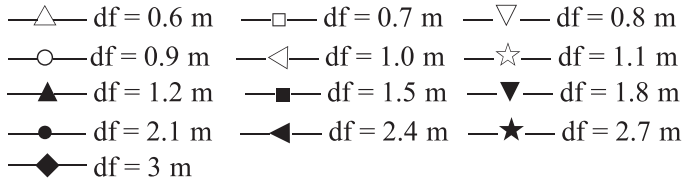

Fig. 13. Variation of "cabin subdivision vibration mode" shapes of $n=3, m=2(b)$ with the depth of the intermediate frame rib for $\mathrm{bf}=0.018 \mathrm{~m}$.

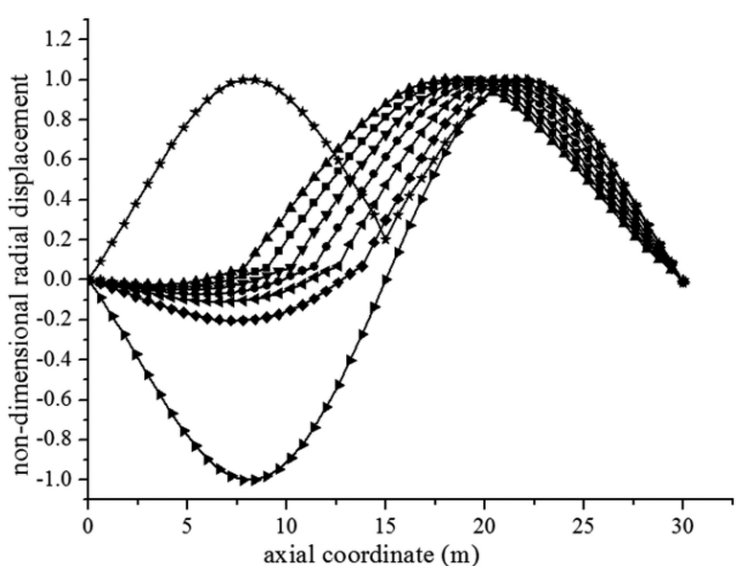

(a) $\mathrm{C}-\mathrm{C}$

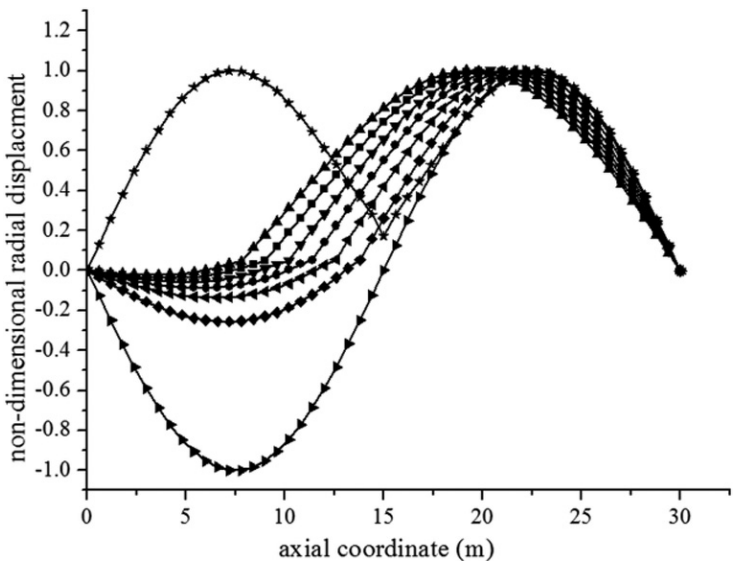

(b) SD-SD

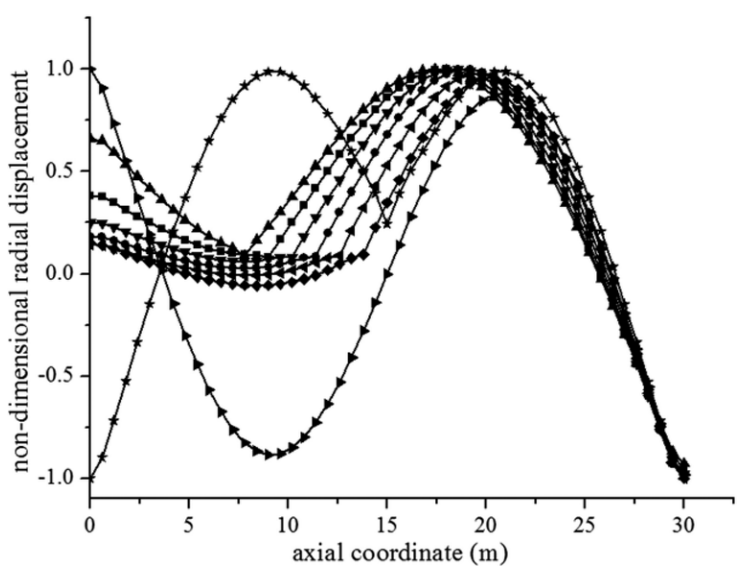

(c) F-F

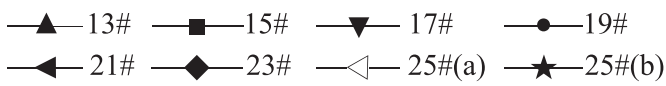

Fig. 14. Variation of vibration mode shapes with positions of the intermediate frame ribs. 
Table 7

Natural frequencies of cylindrical shells with different positions of frame rib

\begin{tabular}{|c|c|c|c|c|c|c|c|c|c|}
\hline \multirow{2}{*}{ B.C } & & \multicolumn{8}{|c|}{ Natural frequencies $(\mathrm{Hz})$} \\
\hline & & 13\# & $15 \#$ & 17\# & 19\# & $21 \#$ & $23 \#$ & $25 \#$ & $25 \#(b)$ \\
\hline $\mathrm{n}=1$ & $\mathrm{C}-\mathrm{C}$ & 26.75 & 26.67 & 26.60 & 26.53 & 26.48 & 26.45 & 26.44 & \\
\hline \multirow[t]{2}{*}{$\mathrm{m}=1$} & SD-SD & 19.11 & 19.07 & 19.02 & 18.99 & 18.96 & 18.94 & 18.94 & \\
\hline & F-F & 39.18 & 39.05 & 38.86 & 38.67 & 38.50 & 38.38 & 38.33 & \\
\hline \multirow[t]{3}{*}{$n=3$} & $\mathrm{C}-\mathrm{C}$ & 27.15 & 27.51 & 27.94 & 28.47 & 29.11 & 29.88 & 30.54 & 31.40 \\
\hline & SD-SD & 26.45 & 26.71 & 27.02 & 27.40 & 27.87 & 28.44 & 28.89 & 29.79 \\
\hline & $\mathrm{F}-\mathrm{F}$ & 27.59 & 27.92 & 28.41 & 29.06 & 29.89 & 30.94 & 32.10 & 32.50 \\
\hline
\end{tabular}

B.C: boundary condition.

Similar conclusions can be made for SD-SD and F-F boundary conditions as those of C-C boundary conditions. All "cabin subdivision vibration mode" frequencies of $\mathrm{n}=2, \mathrm{~m}=2(\mathrm{~b})$ are lower than corresponding "no cabin subdivision vibration mode" frequencies for F-F boundary conditions. As the circumferential wave number increases, the results of the three different kinds of boundary conditions become consistent gradually which means that the effects of boundary conditions become smaller at high circumferential wave number.

Figure 13 shows the variation of "cabin subdivision vibration mode" shapes of $\mathrm{n}=3, \mathrm{~m}=2$ (b) with the depth of the intermediate frame rib for given width $b_{f}=0.018 \mathrm{~m}$ for three different kinds of boundary conditions. For other given width of intermediate frame rib, similar results can be obtained. From Fig. 13 we can see that the vibration mode shapes are always symmetry about the midsection of the cylindrical shell while the displacement of the midsection approaches zero with the increment of the depth of the frame rib from which a conclusion can be made that the effects of the frame rib can be divided into three cases. The first case is that when the size of intermediate frame rib is smaller than the critical size, the frame rib vibrates with the whole cylindrical shell and no "cabin subdivision vibration modes" appear and the natural frequencies of "no cabin subdivision vibration modes" are nearly the same with cylindrical shells with all ordinary ribs. The second case is that when the size of intermediate frame rib is much larger than the critical size, "cabin subdivision vibration modes" appear with the natural frequencies a little larger than corresponding "no cabin subdivision vibration modes" and the whole structure can be considered as two separate cabins of the same length both vibrating at their own natural frequencies which are nearly the same because of the symmetry of the structure. The third case is that when the size of intermediate frame rib is a little larger than the critical size, coupling effects between the two cabins occur because of the existence of the frame rib. The frame rib vibrates with the cylindrical shell but increment of the stiffness of the midsection makes the displacement become smaller. Thus in this case the cylindrical shell neither can be considered vibrating as a whole nor can be considered vibrating as two separate cabins but shows both characteristics.

In the above analysis the frame ribs are all in the midsection of the cylindrical shell which leads to symmetry in the structure. The effects of the number and distributions of the frame ribs are investigated in the following analysis.

Firstly the effects of the distributions of the frame ribs have been investigated. In order to make the conclusions more clearly explained, the computation models considered here are ring stiffened cylindrical shells with only one frame rib with the position changing from 13\# to 25\# which are shown in Fig. 5. The width and the depth of the frame rib are given by $b_{f}=0.054 \mathrm{~m}, d_{f}=0.99 \mathrm{~m}$. The variation of natural frequencies and vibration mode shapes with positions of the frame rib for different boundary conditions is shown in Table 7 and Fig. 14. "25\#(b)" in Table 7 denotes "cabin subdivision vibration modes".

We can see from Table 7 that the lowest beam mode frequency occurs when the frame rib is in the midsection of the cylindrical shell and increment of the distance between the frame rib and the midsection leads to increment of beam mode frequency which proves the conclusions in the previous analysis again: the more mass distributed in the midsection, the lower the beam mode frequency is. "Cabin subdivision vibration modes" and "no cabin subdivision vibration modes" appears only when the frame rib is in the midsection of the cylindrical shell. For other cases both "cabin subdivision vibration modes" and "no cabin subdivision vibration modes" disappear. From the vibration mode shapes shown in Fig. 14 we can see that the cylindrical shell can be considered being divided into two cabins with the longer cabin vibrating with $\mathrm{n}=3, \mathrm{~m}=1$ whose natural frequencies are lower than the shorter cabin. In another word, the large frame rib divides the cylindrical shell into two cabins and each cabin vibrates separately in its own way. When the two cabins are with the same length, they are always vibrating simultaneously at the same 


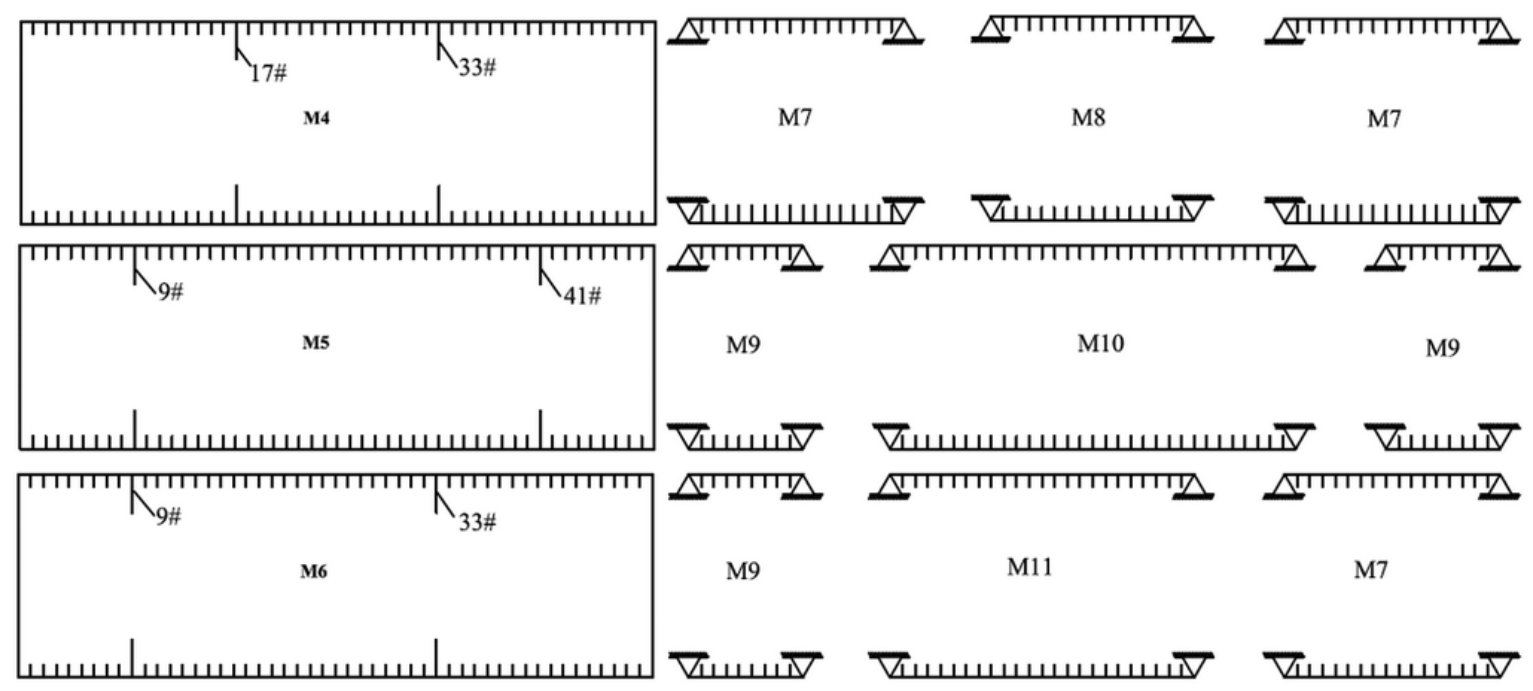

Fig. 15. Cylindrical shells with two frame ribs and separate cabins divided by frame ribs.

natural frequencies with the same vibration mode either vibrating in the same phase or vibrating in opposite phases, so both "cabin subdivision vibration modes" and "no cabin subdivision vibration modes" appear. When the cabins are not with the same length, the natural frequencies of the two cabins with the same vibration mode are different and the cabin with lower natural frequencies begins to vibrate firstly while the other cabin does not vibrate.

Secondly the effects of the number and the distributions of frame ribs are investigated simultaneously. Three computational models are considered here as shown in Fig. 15 which are denoted as model M4, model M5 and model M6 respectively. Frame ribs are approximately evenly distributed in model M4 and are unevenly distributed in model M5 and model M6. The middle cabin is one rib spacing shorter than the two cabins with the same length at the two ends for model M4. The difference between model M5 and model M6 is that for model M5 the length of the two cabins at the two ends are the same while not for model M6. Natural frequencies and vibration mode shapes of $\mathrm{n}=4$ with different boundary conditions are calculated for the reason that the first "cabin subdivision vibration modes" appear as $\mathrm{n}=4$. The results are shown in Table 8 and Figs 16-18.

From Fig. 16 we can see that both "cabin subdivision vibration modes" and "no cabin subdivision vibration modes" appear. For mode 1 and mode 3 the cylindrical shell vibrates as a whole with $\mathrm{n}=4, \mathrm{~m}=3$, especially for C-C boundary condition, or in another word, the cylindrical shell can be considered being divided into three separate cabins with each cabin vibrating with $\mathrm{n}=4, \mathrm{~m}=1$. The difference between mode 1 and mode 3 is that for mode 1 the two cabins at the two ends vibrate in the same phase and in opposite phases with the middle cabin while for mode 3 the three cabins vibrate in the same phase. For mode 2, only the two cabins at the two ends vibrate with $\mathrm{n}=4, \mathrm{~m}=1$ in opposite phases while the middle cabin does not vibrate. This vibration mode appears mainly due to not exactly equally distribution of the frame ribs.

From Figs 17 and 18 we can see that both "cabin subdivision vibration modes" and "no cabin subdivision vibration modes" disappear for model M5 and M6. The cylindrical shell is obviously divided into three cabins by the large frame ribs which can be considered playing a role in imposing displacement or force constraints on the cylindrical shell. For mode 1 , only the middle cabin vibrates with $\mathrm{n}=4, \mathrm{~m}=1$ and the two cabins at the two ends don't vibrate. For mode 2 and mode 3 of model M5 the two cabins at the two ends vibrate simultaneously with n $=4$, $\mathrm{m}=1$ either in the same phase or in opposite phases and the middle cabin doesn't vibrate while for mode 2 and mode 3 of model M6 the two cabins at the two ends also vibrate separately. The reason is that the two cabins of M5 at the two ends have the same length and the same boundary conditions leading them to have the same natural frequencies with the same vibration modes and thus vibrate simultaneously.

In order to explain the results of the above analysis more clearly, natural frequencies of separate cabins divided by large frame ribs are calculated with the results shown in Table 9. Separate cabins denoted as M7 M12 are shown in Fig. 15. The large frame ribs are considered approximately imposing a simply supported constraint or clamped 


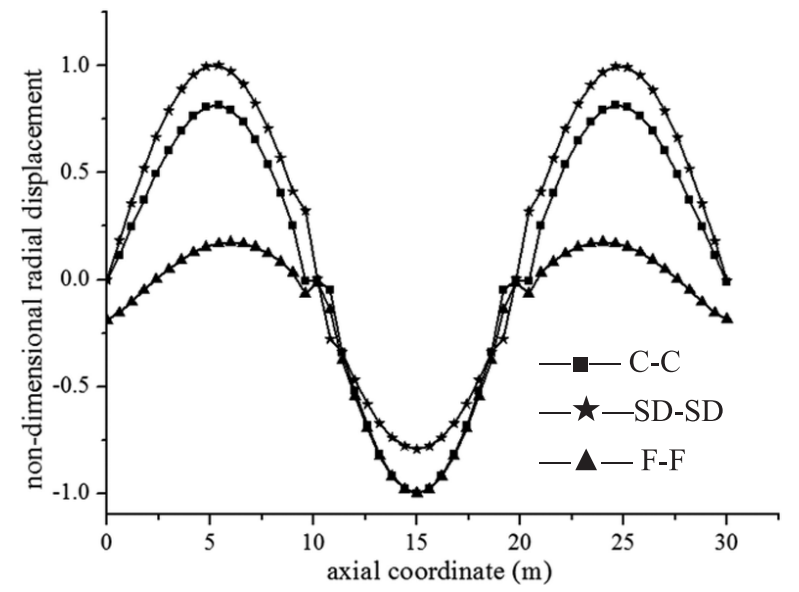

(a) mode 1

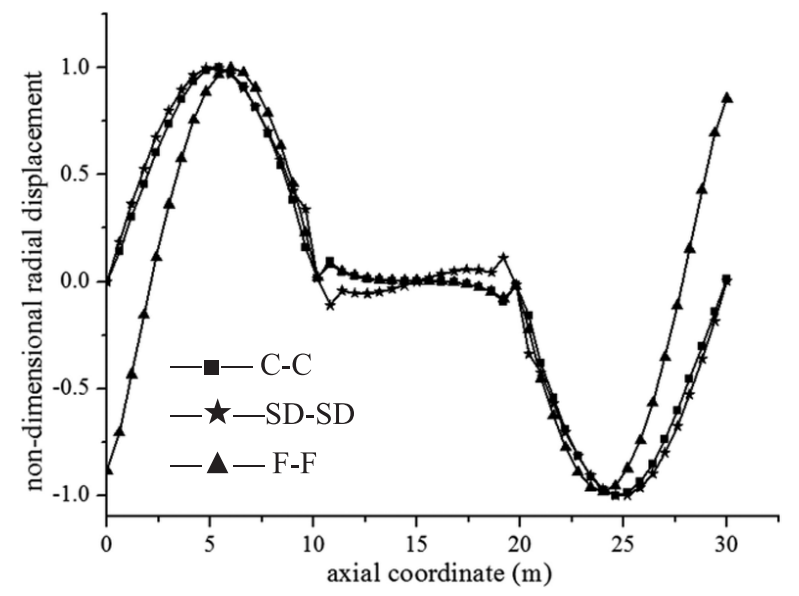

(b) mode 2

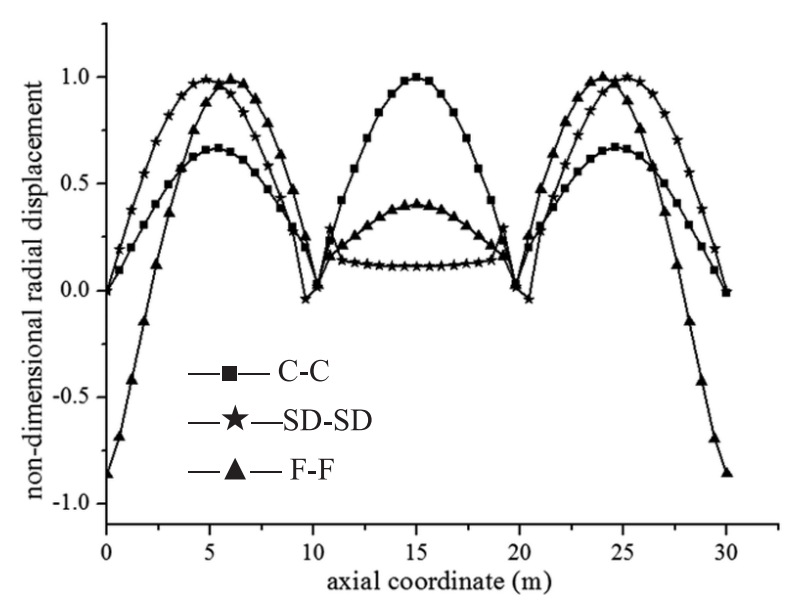

(c) mode 3

Fig. 16. Vibration mode shapes of model M4 when $\mathrm{n}=4$ with different boundary conditions.

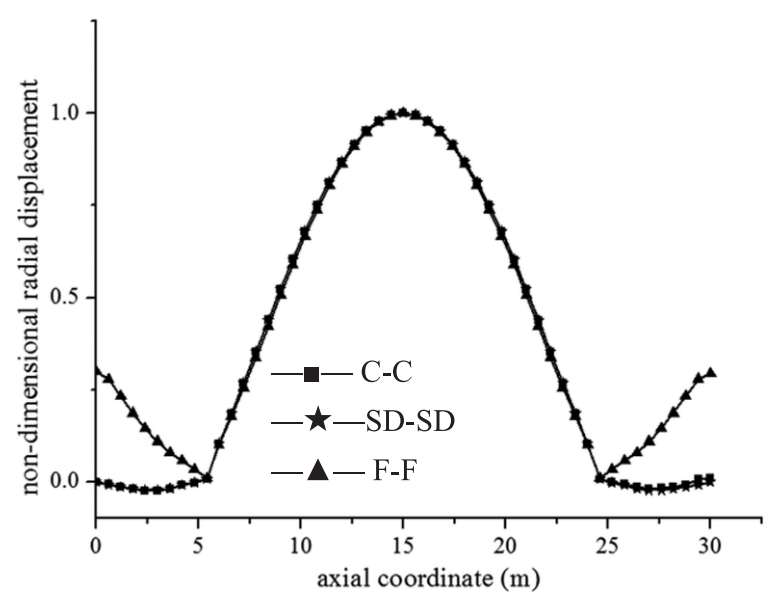

(a) mode 1

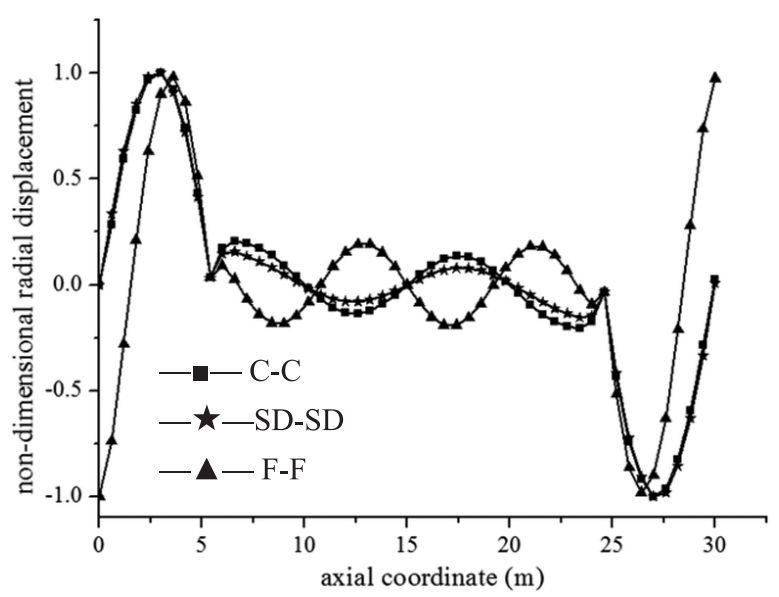

(b) mode 2

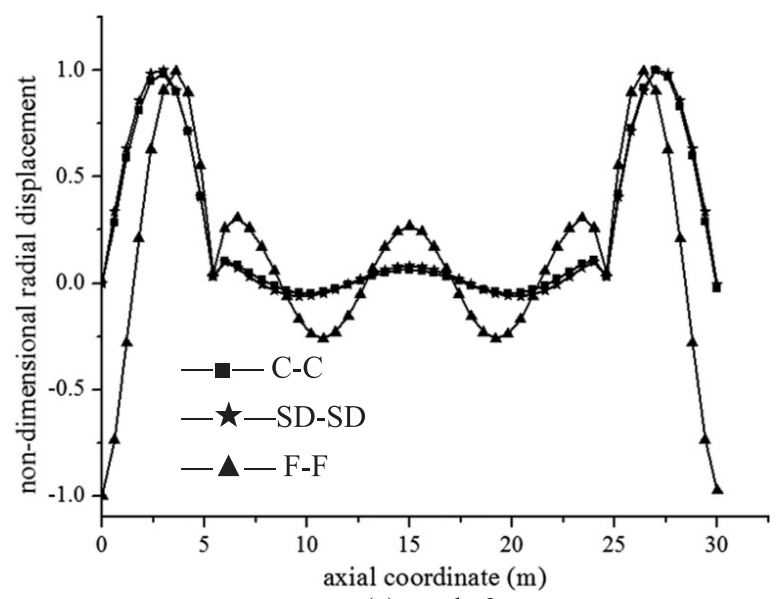

(c) mode 3

Fig. 17. Vibration mode shapes of model M5 when $\mathrm{n}=4$ with different boundary conditions. 
Table 8

Natural frequencies of model M4,model M5 and model M6

\begin{tabular}{|c|c|c|c|c|c|c|c|c|c|}
\hline \multirow{2}{*}{$\begin{array}{l}\text { Boundary } \\
\text { condition }\end{array}$} & \multicolumn{3}{|c|}{ Model M4 } & \multicolumn{3}{|c|}{ Model M5 } & \multicolumn{3}{|c|}{ Model M6 } \\
\hline & Mode 1 & Mode 2 & Mode 3 & Mode 1 & Mode 2 & Mode 3 & Mode 1 & Mode 2 & Mode 3 \\
\hline $\mathrm{C}-\mathrm{C}$ & 51.59 & 51.81 & 52.19 & 47.86 & 64.16 & 64.25 & 48.74 & 51.82 & 64.19 \\
\hline SD-SD & 51.82 & 52.85 & 52.96 & 47.86 & 62.28 & 62.34 & 48.72 & 51.11 & 62.30 \\
\hline F-F & 50.29 & 50.55 & 51.11 & 47.95 & 72.62 & 72.00 & 48.82 & 52.86 & 72.44 \\
\hline
\end{tabular}

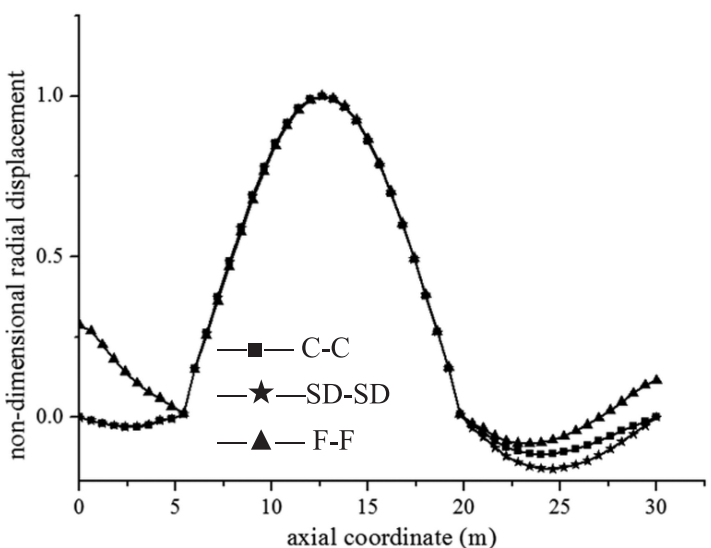

(a) mode 1

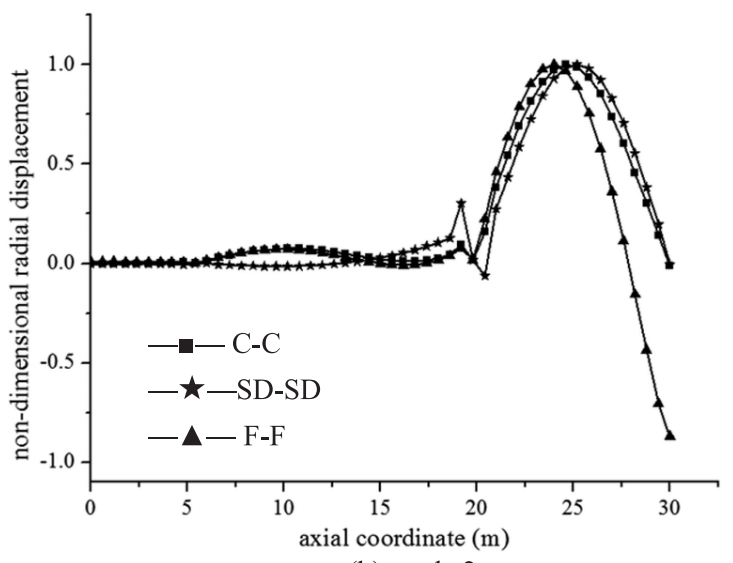

(b) mode 2

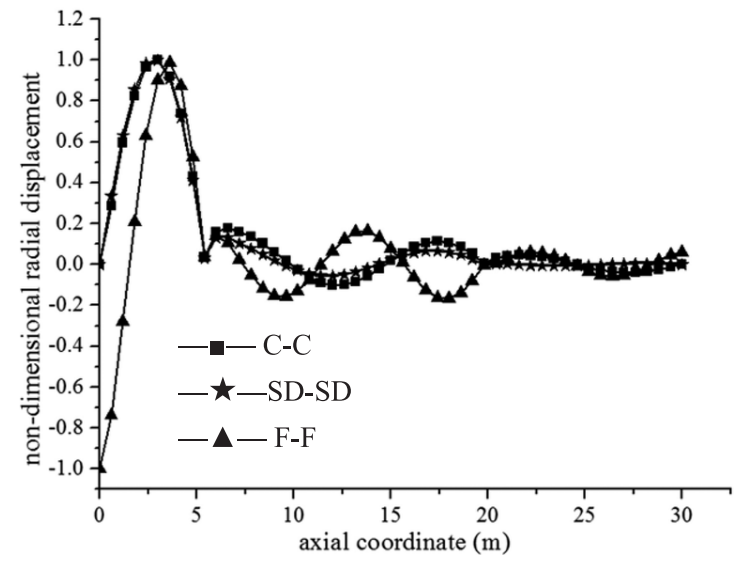

(c) mode 3

Fig. 18. Vibration mode shapes of model M6 when $n=4$ with different boundary conditions.

constraint on the cylindrical shell and thus five kinds of boundary conditions are used. We can see that natural frequencies close to corresponding natural frequencies appearing in Table 8 always can be found in Table 9. For example, the natural frequencies of separate cabins of M7 with C-C and C-SD boundary conditions are $52.33 \mathrm{~Hz}$ and $51.26 \mathrm{~Hz}$ which are quite close to the natural frequency of mode 1 of model M4 with C-C boundary condition which is $51.59 \mathrm{~Hz}$. In this case, the frame ribs can be considered imposing either clamped constraints or simply supported constraints on the cylindrical shell. For other cases, similar phenomenon also can be observed.

From the above analysis a conclusion can be made that existence of intermediate large frame rib divides the cylindrical shell into several cabins vibrating separately no matter the vibration mode shapes are "cabin subdivision vibration modes" or "no cabin subdivision vibration modes" or neither of them. Natural frequencies of the whole structure can also be approximately calculated by free vibrations of corresponding separate cabins with the frame rib imposing simply supported or clamped constraints on one end. 
Table 9

Natural frequencies of separate cabin with different boundary conditions

\begin{tabular}{|c|c|c|c|c|c|}
\hline \multirow{2}{*}{ Model } & \multicolumn{5}{|c|}{ Natural frequencies $(\mathrm{Hz})$} \\
\hline & $\mathrm{C}-\mathrm{C}$ & SD-SD & C-SD & $\mathrm{C}-\mathrm{F}$ & SD-F \\
\hline M7 & 52.33 & 50.29 & 51.26 & 53.56 & 52.39 \\
\hline M8 & 51.27 & 49.31 & 53.59 & 54.70 & 53.45 \\
\hline M9 & 66.40 & 62.60 & 64.35 & 74.97 & 74.21 \\
\hline M10 & 48.02 & 47.57 & 47.77 & 48.00 & 47.44 \\
\hline M11 & 49.26 & 48.29 & 48.73 & 49.44 & 48.84 \\
\hline
\end{tabular}

\section{Conclusions}

Wave Based Method (WBM) which can be recognized as a semi-analytical and semi-numerical method is developed to analyze the free vibration characteristics of ring stiffened cylindrical shells with intermediate large frame ribs for arbitrary boundary conditions. The cylindrical shell is divided into different substructures according to the structure type and the position of discontinuities in WBM model. The motion of each segment of cylindrical shell is described by the equation of Donnel-Mushtari theory and the motions of the ordinary ribs and the frame ribs are both described by the equations of motions of annular circular plates. In contrast with the finite element method, in which the dynamic field variables within each element are expanded in terms of local, non-exact shape functions, usually polynomial approximation, the dynamic field variables in each substructure in WBM are expressed as wave function expansions, which are analytical solutions to the governing dynamic equations of the substructure. Boundary conditions and continuity conditions between different substructures are used to form the final matrix whose size is much smaller than the matrix formed in finite element method. Numerical calculations of WBM model show good agreement with the results calculated by finite element method.

Free vibration characteristics of ring stiffened cylindrical shells with intermediate large frame ribs are studied by WBM. Results of cylindrical shells with single intermediate frame rib show that "cabin subdivision vibration modes" and "no cabin subdivision vibration modes" both appear only when the frame rib is large enough and also in the midsection of the cylindrical shell which leads to symmetry in the structure. The width and the depth of frame rib have little effect on natural frequencies of "no cabin subdivision vibration modes". As the width and the depth of the frame rib increase, "cabin subdivision vibration modes" begin appearing gradually and getting more and more close to those of the cylindrical shells with bulkhead. Natural frequencies of "cabin subdivision vibration modes" increase with the increment of the size of intermediate large frame rib. When the position of the frame rib changes from the midsection to the two ends which destroys the symmetry in the structure, both "cabin subdivision vibration modes" and "no cabin subdivision vibration modes" disappear. The cylindrical shell can be considered being divided into two separate cabins with the same boundary conditions but with different lengths. Each cabin vibrates separately at their own natural frequencies.

If more frame ribs are distributed in the cylindrical shell, both "cabin subdivision vibration modes" and "no cabin subdivision vibration modes" appear when the intermediate frame ribs are equally distributed and disappear when the intermediate frame ribs are not equally distributed. In fact in all cases discussed, the cylindrical shell can be considered being divided into separate cabins with each cabin vibrating at their own natural frequencies. The difference is that when the cabins are with the same length and boundary conditions, their own natural frequencies are the same which leads them to vibrating simultaneously either in the same phase or in opposite phases, while when the cabins are with different lengths and boundary conditions, their own natural frequencies are different which leads each cabin to vibrate separately at their own natural frequencies.

As for beam mode frequencies which always appear, existence of intermediate large frame ribs have little effect on the vibration mode shape, while more mass distributed in the midsection, the lower the beam mode frequencies are.

\section{Acknowledgments}

All the work in this paper obtains great support from the National Natural Science Foundation of China (51179071) and the Fundamental Research Funds for the Central Universities, HUST: 2012QN056. 


\section{References}

[1] A.W. Leissa, Vibration of shell, NASA, Sp-288, 1973.

[2] W. Flügge, Stress in Shells, Springer, Berlin, 1973.

[3] R.N. Arnold and G.B. Warburton, Flexural vibrations of the walls of thin cylindrical shells having freely supported ends, Proceedings of the Royal Society A 197 (1949), 238-256.

[4] C.B. Sharma, Calculation of natural frequencies of fixed-free circular cylindrical shells, Journal of Sound and Vibration 35 (1974), $55-76$.

[5] G.B. Warburton and J. Higgs, Natural frequencies of thin cantilever cylindrical shells, Journal of Sound and Vibration 11 (1970), $335-338$.

[6] R.L. Goldman, Mode shapes and frequencies of clamped-clamped cylindrical shells, AIAA Journal 12 (1974), $1755-1756$.

[7] H.J. Zhou, W.Y. Li, B.L. Lv and W.L. Li, Free vibrations of cylindrical shells with elastic-support boundary conditions, Applied Acoustics 73 (2012), 751-756.

[8] G.D. Galletly, On the in vacuo vibrations of simply supported ring-stiffened cylindrical shell, Proceedings of the second U.S National Congress of Applied Mechanics, Michigan 6 (1954), 98-106.

[9] J.L. Sewall, R.R. Clary and S.A. Leadbetter, An experimental and analytical vibration study of ring-stiffened cylindrical shell structure with various support conditions, NASA TN D-2398 (1964), 52-53.

[10] J.L. Sewall and E.C. Naumann, An experimental and analytical vibration study of thin cylindrical shells with and without longitudinal stiffeners, NASA TN D-4705 (1968), 54-55.

[11] M. Caresta and N.J. Kessissoglou, Structural and acoustic responses of a fluid-loaded cylindrical hull with structural discontinuities, Applied Acoustics 70 (2009), 954-963.

[12] M. Caresta and N.J. Kessissoglou, Reduction of hull-radiated noise using vibroacoustic optimization of the propulsion system, Journal of Ship Research 55 (2011), 149-162.

[13] T. Wah and W.C.L. Hu, Vibration analysis of stiffened cylinders including inter-ring motion, Journal of the Acoustical Society of America 43 (1968), 1005-1016.

[14] Y.K. Tso and C.H. Hansen, Wave propagation through cylinder/plate junctions, Journal of Sound and Vibration 186 (1995), $447-461$.

[15] M. Caresta, Structural and acoustic responses of a submerged vessel, Ph.D. dissertation, University of New South Wales, 2009.

[16] W. Desmet, A wave based prediction technique for coupled vibro-acoustic analysis, Ph.D. dissertation, K.U. Leuven, 1998.

[17] W. Desmet, B.V. Hal, P. Sas and D. Vandepitte, A computationally efficient prediction technique for the steady-state dynamic analysis of coupled vibro-acoustic systems, Advances in Engineering Software 33 (2002), 527-540.

[18] B. Pluymers, W. Desmet, D. Vandepitte and P. Sas, Application of an efficient wave-based prediction technique for the analysis of vibroacoustic radiation problems, Journal of Computational and Applied Mathematics 168 (2004), 353-364.

[19] A.A. Jafari and M. Bagheri, Free vibration of rotating ring stiffened cylindrical shells with non-uniform stiffener distribution, Journal of Sound and Vibration 296 (2006), 353-367. 

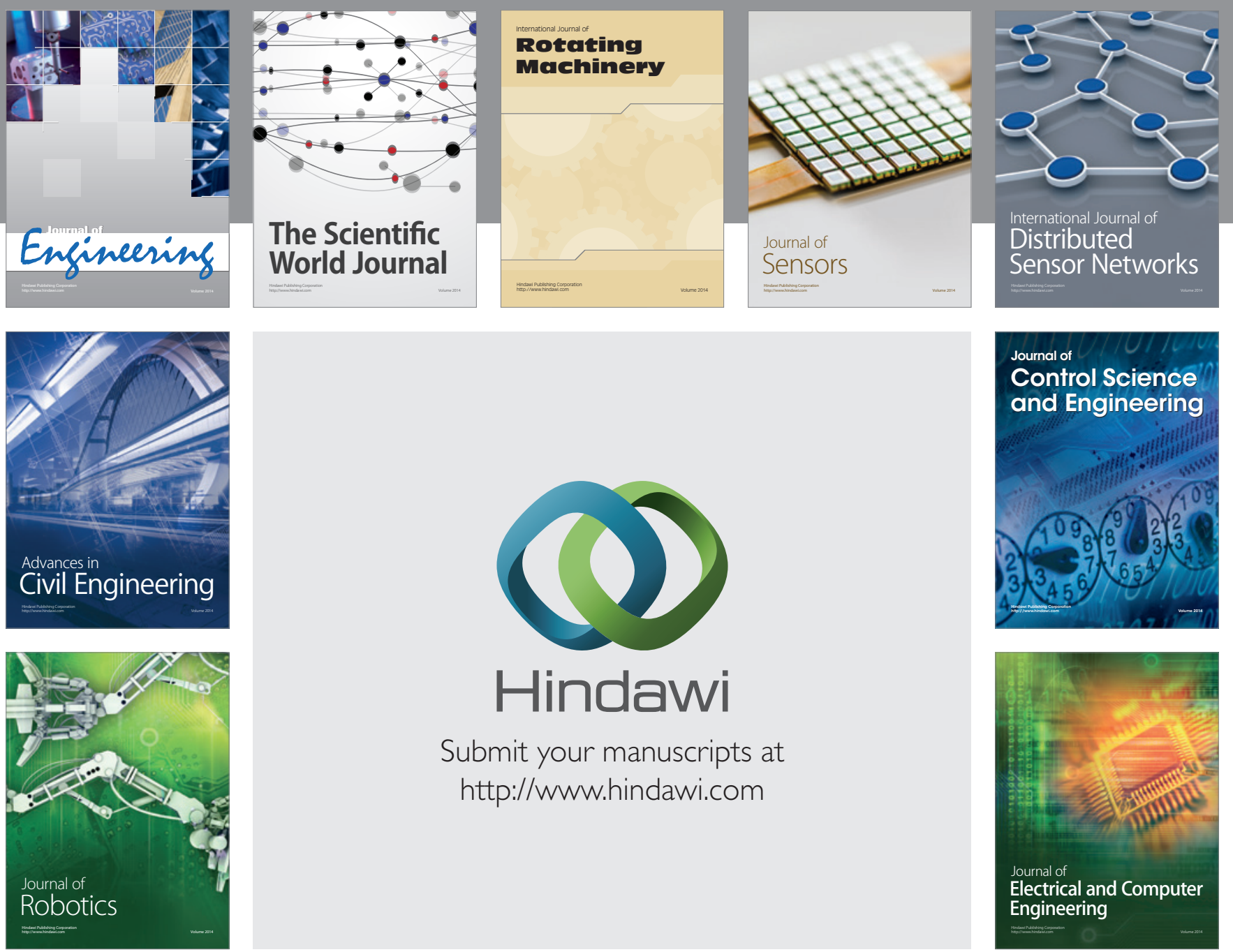

Submit your manuscripts at

http://www.hindawi.com
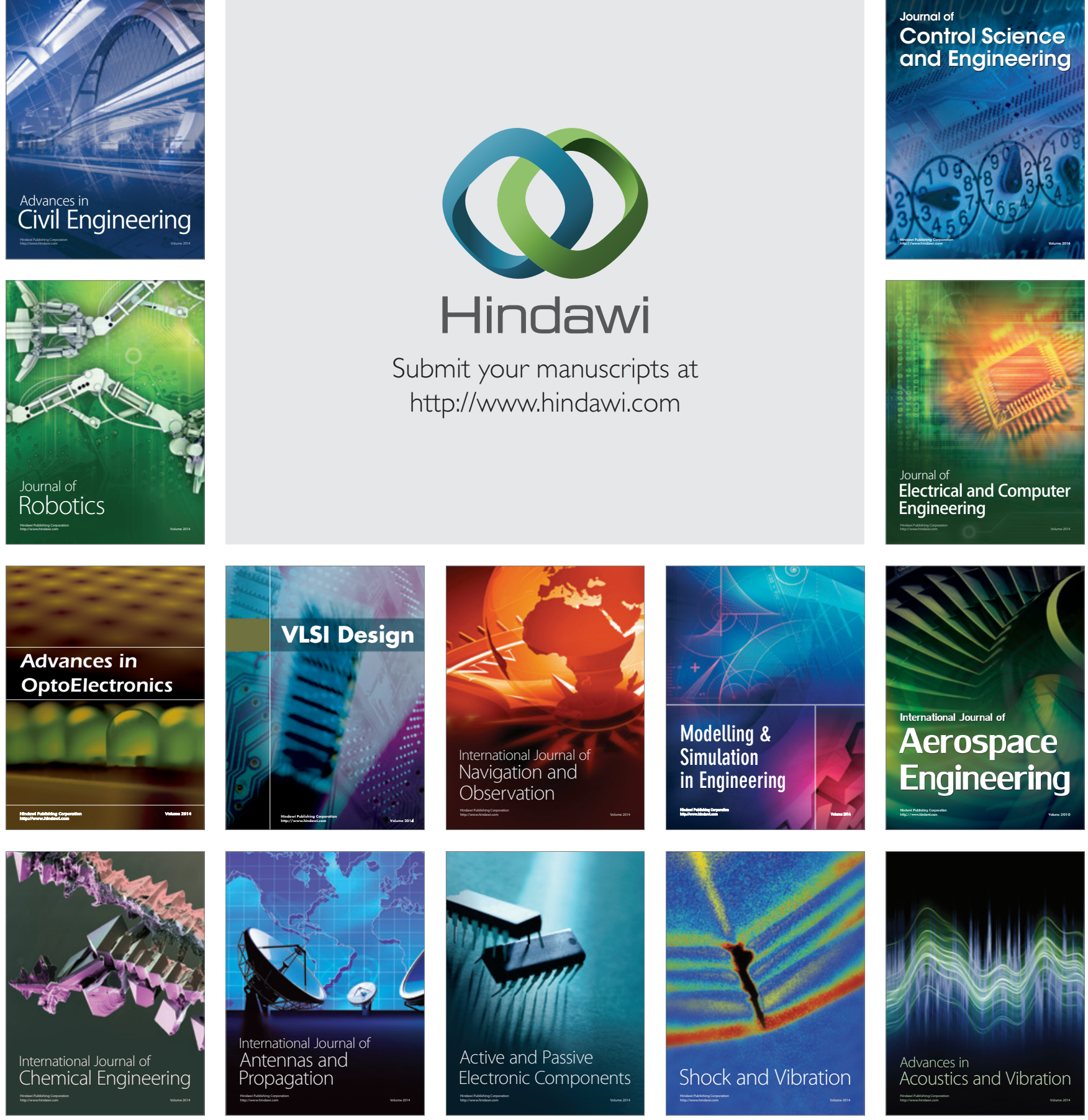